\title{
Membraneless organelles can melt nucleic acid duplexes and act as biomolecular filters
}

\author{
Authors: Timothy J Nott ${ }^{1 *}$, Timothy D Craggs ${ }^{2}$, Andrew J Baldwin ${ }^{1 *}$
}

1. Physical and Theoretical Chemistry, University of Oxford, UK

2. DNA-Protein Interactions Unit, School of Biochemistry, University of Bristol, UK

*correspondence to be addressed to andrew.baldwin@chem.ox.ac.uk and timothy.nott@chem.ox.ac.uk

TOC image:

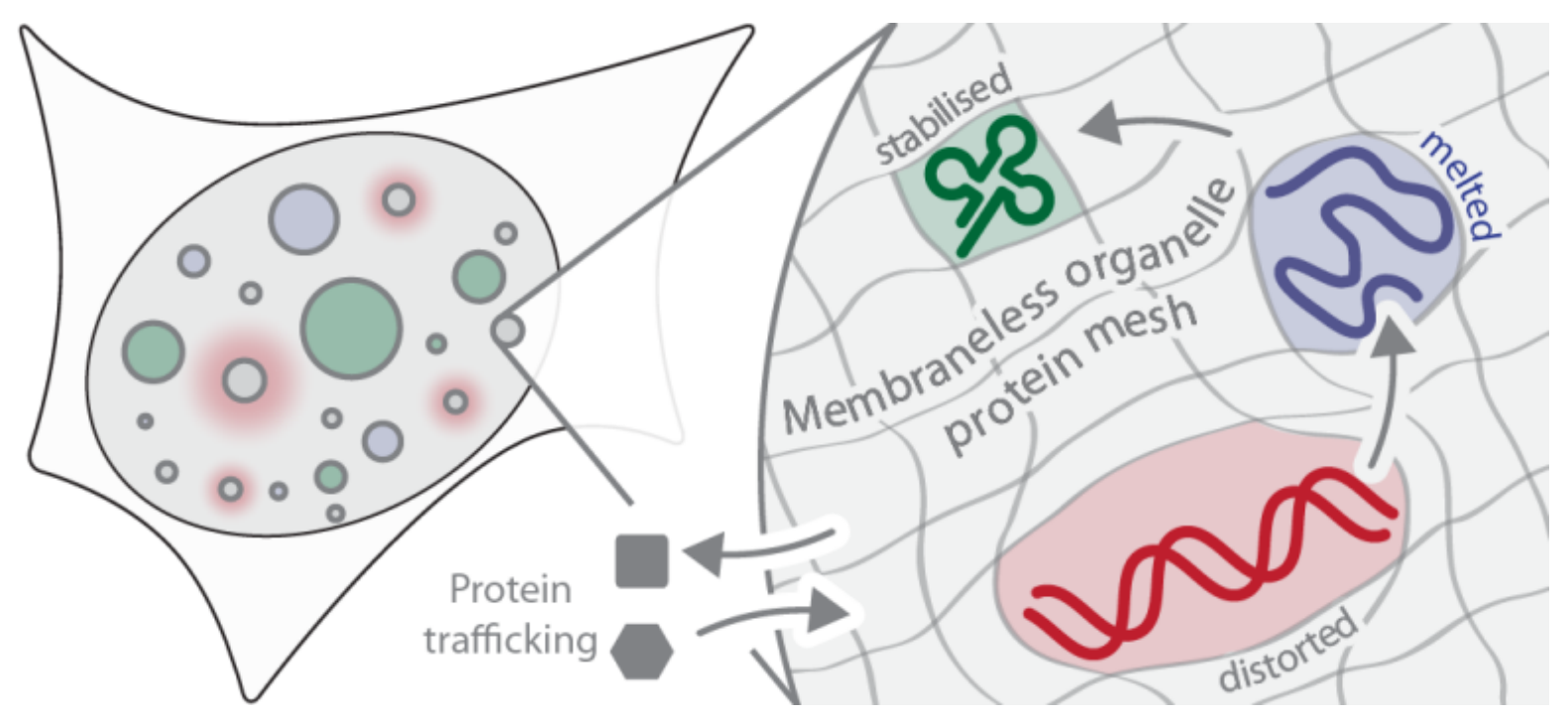

TOC text:

Membraneless organelles are emerging as liquid droplet inside the cell. These bodies are effectively a separate organic phase, with unique biochemical properties. Here we show that the solvent interior of membraneless organelles significantly affects biomolecules. In addition to selectively partitioning and trafficking proteins, they can melt DNA without using ATP. 
Membraneless organelles are cellular compartments made from drops of liquid protein inside a cell. These compartments assemble via the phase separation of disordered regions of proteins in response to changes in the cellular environment and cell cycle. Here, we demonstrate that the solvent environment within the interior of these cellular bodies behaves more like an organic solvent than water. One of the most stable biological structures known, the DNA double helix, can be melted once inside the liquid droplet, while structures formed from regulatory single stranded nucleic acids are stabilised. Moreover, proteins are shown to have a wide range of absorption or exclusion from these bodies, and can act as importers for otherwise excluded nucleic acids, suggesting the existence of a protein-mediated trafficking system. A common strategy in organic chemistry is to utilise different solvents to influence the behaviour of molecules and reactions. These results reveal that by exploiting the interiors of membraneless organelles, cells have also evolved this capability.

\section{Introduction}

Biochemical reactions frequently have conflicting solution requirements, and so cells have evolved a variety of compartmentalisation strategies. A commonly encountered approach is to use membranes, enabling, for example, lysosomes to maintain an acidic $\mathrm{pH}^{1}$, distinct from the more neutral cytosol. In addition to encapsulating water-filled compartments, cells can also form membraneless organelles such as nucleoli $^{2}$, Cajal bodies ${ }^{3}$ and RNA granules ${ }^{4}$. These are micron-sized cellular compartments that are readily observable in the light microscope. They rapidly assemble and dissolve responding to changes in the cellular environment and cell cycle, and are predominantly associated with nucleic acid biochemistry. Recent studies have revealed that they are liquid droplets ${ }^{5-7}$, formed by a phase separation of disordered regions of proteins ${ }^{8-15}$. The concentration of protein in these bodies is such that the disordered chains that constitute their interior are expected to overlap ${ }^{8,16}$ and so the interior can be considered to resemble a mesh-like weave akin to a hydrogel. Most interesting is that the interior of these bodies can be considered distinct from the aqueous environment present in the majority of the cytoplasm and nucleus, and instead show similarity to solvents such as DMSO and acetonitrile in terms of their dielectric constant ${ }^{8}$.

It is not obvious why forming droplets of proteinaceous solvent would be beneficial to an organism. Membraneless organelles can act as filters: nucleoli exclude bulk chromatin in the nucleus ${ }^{17}$ (Fig. 1a and Supplementary Fig. 1a) and stress granules, p-bodies and nuage concentrate RNAs in the cytoplasm in order to regulate their interactions and activities ${ }^{4}$. Recently we demonstrated that model membraneless organelles made of the disordered $\mathrm{N}$-terminus of $\mathrm{Ddx} 4$ protein $\left(\mathrm{Ddx} 4^{\mathrm{N} 1}\right)$ can form bodies similar in 
appearance and characteristics to the nucleolus of cultured cells (Fig. 1b and Supplementary Fig. 1b). These bodies exclude chromatin, yet absorb single stranded DNA molecules ${ }^{8}$ (Fig. 1b). We established previously that these bodies are held together primarily by electrostatic and cation-pi interactions between arginine and phenylalanine residues. This finding motivated us to understand how this interior environment, governed by charged disordered proteins, can influence the behaviour of commonly encountered biological molecules to provide a chemical rationale for why cells would generate membraneless organelles.

In this study, we first produced a range of proteinaceous bodies through expressing proteins predicted to have similar features to $\mathrm{Ddx} 4^{8}$. Each identified protein formed bodies that resemble membraneless organelles, and each, like Ddx4, was able to concentrate single stranded RNA (supplementary Fig. 1c). To go further, we employed a confocal microscopy method to ascertain whether fluorescently labelled double and single stranded DNA and RNA, and a range of proteins, were absorbed or excluded from organelles in vitro ${ }^{8}$.

By quantitatively monitoring the effects of the organelles on these molecules we ascertain that while single stranded RNA and DNA are strongly absorbed in a manner independent of oligonucleotide length, structure in the RNA is stabilised. Moreover, double stranded nucleic acids were melted on entering the bodies. We rationalise this in terms of the distortion absorbing a molecule should have on the underlying mesh-like weave of the organelle interior and the competition between cation-pi interactions between nucleic acids and the protein chains that form the organelle. Contrasting the situation observed for nucleic acids, proteins show a much wider range of absorption or exclusion in a manner that cannot be explained by simple physical quantities such as isoelectric point (pI) or molecular weight. Nevertheless, the behaviour can be quantitatively rationalised by determining the proportion of arginine, tyrosine and proline residues within the solute protein. As with the nucleic acid partitioning, this finding is consistent with competition between the arginine/phenylalanine cation/pi pairs that hold the organelles together and the solute proteins.

Taken together these results reveal that cells can call upon membraneless organelles to offer a wide range of chemistry that is unavailable in the predominantly aqueous interior of the majority of the cell. This approach is analogous to that used by the organic chemist where a synthesis will be optimised by altering the composition of the solvent.

\section{Results}


Previously, we devised an algorithm to predict disordered protein sequences that should form organelles showing sequence similarity to $\operatorname{Ddx} 4$, a primary protein component of nuage ${ }^{8}$. Here, we examined 3 identified sequences, and all formed liquid droplets that resembled membraneless organelles (Supplementary Fig. 1c). Moreover, when fluorescently-labelled single stranded RNA was added, significantly higher fluorescence was observed in the interior of the droplets. These results suggest that the interiors of all tested liquid droplets were similar with physical properties distinct from bulk water, prompting us to determine if the membraneless organelles have biochemical function that extends beyond filtration.

We employed a recently developed confocal microscopy method to ascertain whether fluorescently labelled DNA or RNA oligonucleotides were absorbed or excluded from organelles in vitro ${ }^{8}$. We began by investigating how nucleic acid length affected partitioning within $\mathrm{Ddx} 4^{\mathrm{N} 1}$ organelles using a series of 5'-Cy5 labelled DNA and RNA oligonucleotides derived from concatenated ACTG (DNA) or ACUG (RNA) repeats. Annealing the labelled strand with an equal amount of an unlabelled sense or antisense strand of the same length, produced either single(ss)- or double(ds)-stranded nucleic acids ranging in length from a $12 \mathrm{mer}$ to a $40 \mathrm{mer}$. The nucleic acids were mixed with $\mathrm{Ddx} 4^{\mathrm{N} 1}$ organelles and their relative partitioning, or solubility, was monitored using confocal fluorescence microscopy, and quantified as a partition free energy ( $\Delta G_{\text {part }}$, Fig. 1ci,ii). Unstructured ssRNA was partitioned into the organelle most strongly, followed by ssDNA in a manner that was largely independent of oligonucleotide length. Using fluorescence lifetime measurements, we confirmed that differences in partitioning were attributable to concentration effects and not due to changes in the performance of the fluorescent tag inside and outside the organelles (Supplementary Fig. 1e and supplementary material).

We next sought to investigate the partitioning of structured nucleic acid hairpins, containing a mixture of double-stranded (stem) and single-stranded (loop) regions. A series of 5'-Cy5 labelled DNAs and RNAs comprising 6 to 10 base pair (bp) GC stems and 20 base polyT/U loops displayed increased partitioning over the unstructured single stranded ACTG or ACUG sequences (Fig. 1 ciii). Short, regulatory RNAs such as miRNA, siRNA and piRNA are predicted to adopt hairpin conformations in solution, and are concentrated inside membraneless organelles such as nuage ${ }^{18}$ and RNA granules ${ }^{19,20}$. We tested the partitioning of a mature miRNA (Let-7a) $)^{21,22}$, and three nuage-associated and transposon-derived piRNAs $^{23,24}$ (Fig. 1civ). These physiological RNA hairpins partitioned inside organelles more than the unstructured sequences of similar length.

Contrasting with the case of single-stranded oligonucleotides, highly rigid double-stranded DNA, RNA, and hybrid RNA/DNA duplexes of 20 base pairs or longer were predominantly excluded from Ddx $4^{\mathrm{N} 1}$ 
organelles (Fig. 1c, Supplementary Table 1). Intriguingly, the fluorescence signal from the $12 \mathrm{mer}$ and 16mer duplexes was enriched inside the organelle droplets, though not at the same level as their purely single-stranded equivalents. To understand this result in more detail, we used a Forster resonance energy transfer (FRET) assay to monitor the stability of the 12mer and 24mer DNA duplexes in the presence of the organelles. We added equimolar amounts of either a sense or antisense strand labelled with Cy3 to our original Cy5 ACTG oligonucleotides, to produce FRET-pair labelled ssDNA or dsDNA (Fig. 2ai, Supplementary Fig. 2). Both the partitioning (Fig. 2aii), and inter-strand FRET (Fig. 2aiii), were measured inside and outside of the $\mathrm{Ddx} 4^{\mathrm{N} 1}$ organelles. The single stranded 12 mer exhibited low interstrand FRET both inside and outside organelles, indicating no association between strands in either phase. Conversely, although the partitioning tendencies are opposed, both the $12 \mathrm{mer}$ and $24 \mathrm{mer}$ dsDNAs showed high FRET outside organelles, but markedly diminished FRET inside organelles (Fig. 2aiii, b). To put the observed reduction in FRET into context, we performed a denaturing titration of the 12mer dsDNA with guanidinium chloride $(\mathrm{GdmHCl})$. The loss of FRET signal inside the organelles was consistent with that observed at highly denaturing conditions (4M GdmHCl, Fig. 2c) amounting to a destabilisation of the duplex by 6 orders of magnitude. From these data, we conclude that the interior of $\mathrm{Ddx} 4^{\mathrm{N} 1}$ organelles excludes nucleic acid duplexes, and solubilises single strands (Fig. 2d).

To move towards a mechanistic understanding of the partitioning, the partition free energy was found to vary strikingly as a function of the predicted stability $\left(\Delta G_{\text {stab }}\right)$ of the nucleic acid structures studied (Fig. 3a, Supplementary Table 1). The stabilisation is due to folding in the case of the hairpin structures (Fig. 3bi), and association in the case of double stranded oligonucleotides (Fig. 3bii). Nucleic acids with $\Delta G_{\text {stab }}$ less than $-125 \mathrm{~kJ} \mathrm{~mol}^{-1}$ were partitioned inside, whereas those with greater $\Delta G_{\text {stab }}$ were excluded. The data were analysed in terms of a thermodynamic model, which links the stability of the oligonucleotide structures inside and outside of the organelles to the observed partitioning behaviour (Fig. 3bi, ii and Supplementary Information). From this analysis, the ratio of double to single stranded oligonucleotides was lower inside the organelles than outside, consistent with our experimental FRET results (Fig. 2). Similarly, as the partition free energy of single stranded RNA was less than that observed for structured, physiologically relevant RNAs, the secondary structure is effectively stabilised inside the organelles (Fig. $3 c)$.

A quantitative analysis of how the thermodynamic parameters vary with overall number of base pairs revealed that the contribution to the partition free energies by individual base pairs within an oligonucleotide decreases as the sequence is lengthened (Fig. 3c (solid lines), Supplementary Fig. 3c). This scaling is quantitatively consistent with 'topological frustration' inside the organelles, observed previously in amyloid fibrils ${ }^{25}$ where shorter polymers provide more free energy per unit residue than 
longer sequences. Taken together, the crowded interior of the organelle tends to favour compact oligonucleotide structures over extended or rigid conformations (Fig. 3c, d), which can be quantitatively explained in terms of the ease with which molecules can fit into the mesh-like weave of $\mathrm{Ddx} 4^{\mathrm{N} 1}$ proteins that form the interior of the organelle, without distorting any underlying structure.

To complement the characterisation of organelle partitioning of oligonucleotides, we mixed a range of fluorescently tagged proteins with organelles and measured their partition free energies (Supplementary Table 2). The quantum yield of proteins such as GFP and CFP have been shown to be independent of solution conditions and so, to a good approximation, any fluorescence observed can be taken to be a measure of the distribution of the concentration of proteins bearing a folded chromophore ${ }^{26-28}$ (Supplementary Fig. 1f and supplementary material).

Proteins conjugated to GFP, CFP or YFP showed a greater range of partitioning than we observed for the nucleic acids (Fig. 4a, Supplementary Fig. 4ai). A range of tagged variants of Ddx4 and PiwiL1, a nuage protein expressed during the latter stages of spermiogenesis, were all absorbed. By contrast, two fluorescently tagged small heat shock protein (Hsp) oligomers of Hsp16.5 and $\alpha \mathrm{B}$-crystallin (average oligomer weights 1.1 and 1.4 MDa, respectively) were both strongly excluded from the organelles. The extent to which the proteins tested are absorbed or excluded cannot be explained simply in terms of pI or molecular weight (Supplementary Fig. 4ai) suggesting the organelles naturally have a complex recognition scheme for protein entry and trafficking. Nonetheless, the observed partitioning can be correlated with the amino acid compositions of the target proteins. Whereas most three parameter correlations may be of little physical or mechanistic meaning, others stand out as highly rationalisable. For example, among the proteins tested, accumulation into or depletion from $\mathrm{Ddx} 4^{\mathrm{N} 1}$-rich droplets can be quantitatively described by knowledge of the proline, arginine and tyrosine content (Supplementary Fig. 4bi, ii). As the interactions that hold the droplets together are based on quadrupolar interactions between phenylanalanines and $\operatorname{arginines}^{8}$, being arginine rich will allow a protein to out-compete $\operatorname{Ddx} 4$ arginine/phenylalanine interactions and be absorbed more highly.

Finally, a series of GFP proteins were introduced that varied in surface charge ${ }^{29}$. Both an acidic GFP (-30 net charge, $\left.\mathrm{GFP}^{-30}\right)$ and a basic GFP $\left(+15\right.$ net charge, $\left.\mathrm{GFP}^{+15}\right)$ were absorbed inside the organelles more than wild-type GFP (-7 net charge, GFP ${ }^{\mathrm{WT}}$, Fig. 4a). Such supercharged GFP proteins have been used as delivery vehicles for various nucleic acids into live cells ${ }^{30}$. We therefore tested whether $\mathrm{GFP}^{+15}$, the most highly absorbed protein, could import an otherwise excluded nucleic acid into $\mathrm{Ddx} 4^{\mathrm{N} 1}$ organelles. For this we pre-incubated GFP ${ }^{\mathrm{WT}}$ and $\mathrm{GFP}^{+15}$ with 40 mer or 24 mer dsDNA (Fig. 1c), and introduced the mixtures to $\mathrm{Ddx} 4^{\mathrm{N} 1}$ organelles. Partitioning of $\mathrm{GFP}^{\mathrm{WT}}$ and the dsDNAs were largely unchanged when premixed 
together (Fig. 4bi, and Supplementary Fig. 4aii). However, in the presence of $\mathrm{GFP}^{+15}$, the dsDNA partitioning was reversed, with DNA now being concentrated inside the organelles (Fig. 4bi, Supplementary Fig. 4aii). FRET between the strands of the imported duplex was diminished inside the organelles, indicating that once imported, the double stranded DNA was melted (Fig. 4bii, iii, Supplementary Fig. 4c).

\section{Discussion}

Membraneless organelles have been identified as an important mechanism for compartmentalisation in cells. The interior of these bodies, similar to intracellular lipid droplets ${ }^{31}$, are liquid, and constitute a solvent phase present within cells that is distinct from water. In the case of membraneless organelles, the interior would be expected to be highly polar containing a large amount of water, whereas in lipid droplets, composed of triacylglycerols and sterols, would be expected be less polar and exclude more water. One property of different solvent systems is that they can partition biomolecules with no input of ATP. Here we demonstrate that in addition to partitioning, membraneless organelles can affect the physical and structural properties of biomolecules.

Individual proteins and oligonucleotides together exhibit a complex but predictable set of tendencies to enter the bodies studied here. The interior of the organelles can melt double stranded DNA, destabilising it by up to 6 orders of magnitude without the need for ATP while single stranded structures can be simultaneously stabilised. The local destabilisation and remodelling of DNA and RNA is a property generally attributed to specific ATP-dependent helicase enzymes. Our results reveal that the interior of membraneless organelles behave like passive helicases, and suggest that enzyme-catalysed processes such as nucleic acid remodelling, polymerisation and cleavage could be modulated when performed in this environment.

The wild type $\mathrm{Ddx} 4$ protein is a primary constituent of nuage membraneless organelles, occurring with a DEAD box helicase domain in place of the YFP moiety in Ddx $4{ }^{\mathrm{YFP}}$ studied here. Both constructs form bodies in cells that closely resemble membraneless organelles (ref 8; Supp Figure 2c), which is consistent with the observation that the disordered tails are primarily responsible for organelle formation ${ }^{8}$. These findings suggest more generally that cells can flank proteins with these disordered tails in order to traffic them towards specific membraneless organelles, in order to further functionalise these bodies.

The physical basis of the observed partitioning trends is consistent with the physical forces holding the membraneless organelles together. We have shown previously that Ddx4 organelles and those related to them are held together by electrostatic and cation-pi interactions, predominantly between arginine and 
phenylalanine residues. Single stranded nucleic acids would be expected to have an excess of flexible nucleotides, with their nitrogenous bases exposed to the local solvent environment. These would be capable of competing for interactions with arginine residues within the organelle protein, resulting in their net absorption. In the context of double stranded nucleic acids, the same effect would be expected to favour single stranded oligonucleotides inside the organelles, contributing to overall duplex destabilisation. Moreover, compact structures are favoured by the organelles due to the minimal disruption they cause in the underlying structure of the organelle proteins. Finally, in a similar way, exposed arginine or tyrosine in proteins would be expected to be compatible with arginine/phenylalanine network holding the organelles together.

In this work we show that three proteins with similarity to $\mathrm{Ddx} 4$, associated with the regulation of transcription, translation, and the assembly of stress granules, form proteinaceous droplets with similar affinities for single stranded nucleic acids, and that these behaviours can be directly attributed to the intermolecular forces holding the organelles together. It is highly plausible that membraneless organelles held together by different inter-molecular forces will have novel properties distinct from those shown here.

Overall, we have demonstrated that the interior of membraneless organelles can have very different biochemical properties to the bulk aqueous phase of the cell. Taken together, these results suggest that organisms routinely create and destroy membraneless organelles in order to take advantage of their tailored biochemical properties.

\section{Methods}

\section{HeLa Cell culture}

HeLa cells were cultured as previously described ${ }^{8}$. Briefly, cells were grown on $25 \mathrm{~mm}$ glass coverslips in growth media (high glucose DMEM containing $20 \mathrm{mM}$ HEPES pH 7.4, 10\% FBS and antibiotics at $37^{\circ} \mathrm{C}$ and $\left.5 \% \mathrm{CO}_{2}\right)$. Ddx4 constructs ( $\mathrm{Ddx} 4{ }^{\mathrm{YFP}}$ and $\left.\mathrm{Ddx} 4{ }^{\mathrm{YFP}} \mathrm{FtoA}\right)$ were expressed in HeLa cells from pcDNA $3.1+$ (Invitrogen) plasmids by transient transfection utilizing the Effectene (Qiagen) or polyethylenimine (PEI) methods. Transfections were carried out according to the manufacturer's instructions and used 0.5 $1 \mu \mathrm{g}$ plasmid DNA per coverslip. Immunofluorescence and imaging of fixed HeLa cells was performed as previously described ${ }^{8}$.

\section{Protein expression and purification}


Recombinant proteins for both organelle formation and partitioning were expressed from IPTG-inducible plasmids in $E$. coli cells overnight at $20^{\circ} \mathrm{C}$. Cell pellets were suspended in buffer $(50 \mathrm{mM}$ Tris $\mathrm{pH} 8.0,500$ $\mathrm{mM} \mathrm{NaCl}, 5 \mathrm{mM} \mathrm{DTT}$ ) and lysed by homogenisation. Proteins were first purified by affinity chromatography (GST-4b beads, GE Healthcare Life Sciences or Ni-NTA, Invitrogen). The GST tag was removed with TEV-protease, and the target protein further purified and buffer exchanged by size exclusion chromatography into storage buffer (20 mM Tris pH 8.0, $300 \mathrm{mM} \mathrm{NaCl}, 5 \mathrm{mM}$ TCEP). Purified proteins were centrifugally concentrated and flash frozen in liquid nitrogen and stored at $-80^{\circ} \mathrm{C}$. The sequences of all proteins used in this study are summarised in table S3.

\section{Oligonucleotide sample preparation}

DNA and RNA oligonucleotides, including those combined with the fluorescent Cy3 and Cy5 dyes, were purchased from SIGMA and delivered as lyophilised samples. Stocks at $100 \mu \mathrm{M}$ were made by resuspending the oligonucleotides in TE buffer (10 $\mathrm{mM}$ Tris $\mathrm{pH} 8.0$ at RT, $1 \mathrm{mM}$ EDTA) and stored at $20^{\circ} \mathrm{C}$. Lower concentration working stocks were made by further dilution with TE buffer. Prior to partitioning experiments, oligonucleotide mixtures (sense + sense or sense + antisense) were heated to $>95^{\circ} \mathrm{C}$ for 2 minutes, and allowed to cool to room temperature over the course of 90-120 minutes. Hairpin

oligonucleotides were heated to $>95^{\circ} \mathrm{C}$ for 2 minutes and snap-cooled on ice before equilibrating at room temperature for 5 minutes.

\section{Experimental determination of oligonucleotide stability $\left(\Delta G_{\text {stab }}\right)$}

To compare with the theoretical estimates, the stability of the duplexes formed by the $12 \mathrm{mer}, 16 \mathrm{mer}$ and 20mer ACTG dsDNA, samples were measured using a Chirascan circular dichroism spectrophotometer (Applied Photophysics), equipped with Series 800 Temperature Controller (AlphaOmega Instruments). Oligonucleotide samples were first heated to at least $85^{\circ} \mathrm{C}$ for 5 minutes, followed by cooling at $1^{\circ} \mathrm{C} \min ^{-1}$ to $20^{\circ} \mathrm{C}$. Absorbance at $278 \mathrm{~nm}$ was monitored $\left(1 \mathrm{~nm}\right.$ bandwidth, $1^{\circ} \mathrm{C}$ step size, $0.5 \mathrm{sec}$ per time point, 8 repeats) as the samples were cooled. The temperature at which the samples contained $50 \%$ duplex were derived from the decrease in hyperchromicity as the oligonucleotides annealed. Annealing profiles were measured at 4 concentrations per oligonucleotide sample, from which it was possible to derive $\Delta G_{\text {stab }}$.

\section{Microscopy}

$\mathrm{Ddx} 4^{\mathrm{N} 1}$ organelle partitioning of fluorescent nucleic acids and proteins was imaged using a Leica TCS SP5II microscope equipped with a motorised stage and HCX PL APO CS 40x NA 1.3 oil immersion objective. Illumination was provided by Argon (458, 488 and $514 \mathrm{~nm}$ ) and Helium-Neon (543 and 633 $\mathrm{nm}$ ) lasers. Imaging scan speed was $400 \mathrm{~Hz}$ with a format of 512 x 512 pixels at 8 bit depth. Z-stacks 
were taken $+/-10 \mu \mathrm{m}$ from the brightest plane of the sample in $1 \mu \mathrm{m}$ increments. Experimental parameters (laser intensity, detector sensitivity etc.) remained constant for each set of experiments and associated controls. Typical excitation and emission schemes for the fluorophores used in partitioning experiments are summarised in table S4. FRET measurements made between $\mathrm{Cy} 3$ and Cy5-labelled oligonucleotides were made using the same Leica TCS SP5II microscope setup. Detailed description of the analysis of FRET data can be found in the supplementary material.

\section{Measurement of FRET by fluorimeter}

Fluorescence measurements were made of the FRET-pair ssDNA and dsDNA 12mer ACTG samples in the absence of organelles but in the presence of increasing concentrations of the denaturant $\mathrm{GdmHCl}$ using a Perkin Elmer LS-50B fluorescence spectrometer. The 12mer ACTG dsDNA FRET-pair was chemically denatured using guanidinium chloride $(\mathrm{GdmHCl} 0-6 \mathrm{M}, \mathrm{pH} 8.0)$. At each titration point the total concentration of DNA was $2 \mu \mathrm{M}$ (i.e. sense and sense/antisense strands each at $1 \mu \mathrm{M}$ ), and the $\mathrm{NaCl}$ concentration was fixed at $150 \mathrm{mM}$. 


\section{References}

1. Luzio, J. P., Pryor, P. R. \& Bright, N. A. Lysosomes: fusion and function. Nat. Rev. Mol. Cell Biol. 8, 622-632, (2007).

2. Boisvert, F. M., van Koningsbruggen, S., Navascues, J. \& Lamond, A. I. The multifunctional nucleolus. Nat. Rev. Mol. Cell Biol. 8, 574-585, (2007).

3. Nizami, Z., Deryusheva, S. \& Gall, J. G. The Cajal Body and Histone Locus Body. Csh. Perspect. Biol. 2, (2010).

4. Anderson, P. \& Kedersha, N. RNA granules: post-transcriptional and epigenetic modulators of gene expression. Nat. Rev. Mol. Cell Biol. 10, 430-436, (2009).

5. Brangwynne, C. P., Eckmann, C. R., Courson, D. S., Rybarska, A., Hoege, C. et al. Germline P Granules Are Liquid Droplets That Localize by Controlled Dissolution/Condensation. Science 324, 1729-1732, (2009).

6. Brangwynne, C. P., Mitchison, T. J. \& Hyman, A. A. Active liquid-like behavior of nucleoli determines their size and shape in Xenopus laevis oocytes. Proc. Natl. Acad. Sci. USA 108, 43344339, (2011).

7. Berry, J., Weber, S. C., Vaidya, N., Haataja, M. \& Brangwynne, C. P. RNA transcription modulates phase transition-driven nuclear body assembly. Proc. Natl. Acad. Sci. USA 112, E5237-E5245, (2015).

8. Nott, T. J., Petsalaki, E., Farber, P., Jervis, D., Fussner, E. et al. Phase Transition of a Disordered Nuage Protein Generates Environmentally Responsive Membraneless Organelles. Mol. Cell 57, 936-947, (2015).

9. Li, P. L., Banjade, S., Cheng, H. C., Kim, S., Chen, B. et al. Phase transitions in the assembly of multivalent signalling proteins. Nature 483, 336-U129, (2012).

10. Elbaum-Garfinkle, S., Kim, Y., Szczepaniak, K., Chen, C. C.-H., Eckmann, C. R. et al. The disordered $P$ granule protein LAF-1 drives phase separation into droplets with tunable viscosity and dynamics. Proc. Natl. Acad. Sci. USA 112, 7189-7194, (2015).

11. Weber, S. C. \& Brangwynne, C. P. Inverse Size Scaling of the Nucleolus by a ConcentrationDependent Phase Transition. Curr. Biol. 25, 641-646, (2015).

12. Patel, A., Lee, H. O., Jawerth, L., Maharana, S., Jahnel, M. et al. A Liquid-to-Solid Phase Transition of the ALS Protein FUS Accelerated by Disease Mutation. Cell 162, 1066-1077, (2015).

13. Lin, Y., Protter, D. S., Rosen, M. K. \& Parker, R. Formation and Maturation of Phase-Separated Liquid Droplets by RNA-Binding Proteins. Mol. Cell 60, 208-219, (2015).

14. Molliex, A., Temirov, J., Lee, J., Coughlin, M., Kanagaraj, A. P. et al. Phase Separation by Low Complexity Domains Promotes Stress Granule Assembly and Drives Pathological Fibrillization. Cell 163, 123-133, (2015).

15. Jiang, H., Wang, S., Huang, Y., He, X., Cui, H. et al. Phase Transition of Spindle-Associated Protein Regulate Spindle Apparatus Assembly. Cell 163, 108-122, (2015).

16. Burke, K. A., Janke, A. M., Rhine, C. L. \& Fawzi, N. L. Residue-by-Residue View of In Vitro FUS Granules that Bind the C-Terminal Domain of RNA Polymerase II. Mol. Cell 60, 231-241, (2015).

17. Swedlow, J. R. \& Lamond, A. I. Nuclear dynamics: where genes are and how they got there. Genome Biol. 2, (2001).

18. Meikar, O., Da Ros, M., Liljenback, H., Toppari, J. \& Kotaja, N. Accumulation of piRNAs in the chromatoid bodies purified by a novel isolation protocol. Exp. Cell Res. 316, 1567-1575, (2010). 
19. Han, T. N. W., Kato, M., Xie, S. H., Wu, L. C., Mirzaei, H. et al. Cell-free Formation of RNA Granules: Bound RNAs Identify Features and Components of Cellular Assemblies. Cell 149, 768779, (2012).

20. Kato, M., Han, T. N. W., Xie, S. H., Shi, K., Du, X. L. et al. Cell-free Formation of RNA Granules: Low Complexity Sequence Domains Form Dynamic Fibers within Hydrogels. Cell 149, 753-767, (2012).

21. Pasquinelli, A. E., Reinhart, B. J., Slack, F., Martindale, M. Q., Kuroda, M. I. et al. Conservation of the sequence and temporal expression of let-7 heterochronic regulatory RNA. Nature 408, 86$89,(2000)$.

22. Reinhart, B. J., Slack, F. J., Basson, M., Pasquinelli, A. E., Bettinger, J. C. et al. The 21-nucleotide let-7 RNA regulates developmental timing in Caenorhabditis elegans. Nature 403, 901-906, (2000).

23. Aravin, A. A., Sachidanandam, R., Bourc'his, D., Schaefer, C., Pezic, D. et al. A piRNA pathway primed by individual transposons is linked to de novo DNA methylation in mice. Mol. Cell 31, 785-799, (2008).

24. Watanabe, T., Takeda, A., Tsukiyama, T., Mise, K., Okuno, T. et al. Identification and characterization of two novel classes of small RNAs in the mouse germline: retrotransposonderived siRNAs in oocytes and germline small RNAs in testes. Genes Dev. 20, 1732-1743, (2006).

25. Baldwin, A. J., Knowles, T. P. J., Tartaglia, G. G., Fitzpatrick, A. W., Devlin, G. L. et al. Metastability of Native Proteins and the Phenomenon of Amyloid Formation. J. Am. Chem. Soc. 133, 1416014163, (2011).

26. Borst, J. W., Hink, M. A., van Hoek, A. \& Visser, A. J. W. G. Effects of refractive index and viscosity on fluorescence and anisotropy decays of enhanced cyan and yellow fluorescent proteins. $J$. Fluoresc. 15, 153-160, (2005).

27. Suhling, K., Davis, D. M., Petrasek, Z., Siegel, J. \& Phillips, D. The influence of the refractive index on EGFP fluorescence lifetimes in mixtures of water and glycerol. P. Soc. Photo-Opt. Ins. 2, 92101, (2001).

28. Craggs, T. D. Green fluorescent protein: structure, folding and chromophore maturation. Chem. Soc. Rev. 38, 2865-2875, (2009).

29. Lawrence, M. S., Phillips, K. J. \& Liu, D. R. Supercharging proteins can impart unusual resilience. J. Am. Chem. Soc. 129, 10110-10112, (2007).

30. McNaughton, B. R., Cronican, J. J., Thompson, D. B. \& Liu, D. R. Mammalian cell penetration, siRNA transfection, and DNA transfection by supercharged proteins. Proc. Natl. Acad. Sci. USA 106, 6111-6116, (2009).

31. Thiam, A. R., Farese, R. V. \& Walther, T. C. The biophysics and cell biology of lipid droplets. Nat. Rev. Mol. Cell Biol. 14, 775-786, (2013).

32. Pedelacq, J. D., Cabantous, S., Tran, T., Terwilliger, T. C. \& Waldo, G. S. Engineering and characterization of a superfolder green fluorescent protein. Nat. Biotechnol. 24, 79-88, (2006).

33. Cao, J. F., Wu, T., Hu, C., Liu, T., Sun, W. et al. The nature of the different environmental sensitivity of symmetrical and unsymmetrical cyanine dyes: an experimental and theoretical study. Phys. Chem. Chem. Phys. 14, 13702-13708, (2012).

34. Muddana, H. S., Morgan, T. T., Adair, J. H. \& Butler, P. J. Photophysics of Cy3-Encapsulated Calcium Phosphate Nanoparticles. Nano Lett. 9, 1559-1566, (2009).

35. Markham, N. R. \& Zuker, M. UNAFold: software for nucleic acid folding and hybridization. Methods Mol. Biol. 453, 3-31, (2008).

36. Schindelin, J., Arganda-Carreras, I., Frise, E., Kaynig, V., Longair, M. et al. Fiji: an open-source platform for biological-image analysis. Nature methods 9, 676-682, (2012). 
37. Clegg, R. M. Fluorescence Resonance Energy-Transfer and Nucleic-Acids. Methods Enzymol. 211, 353-388, (1992).

38. Gatzogiannis, E., Chen, Z. X., Wei, L., Wombacher, R., Kao, Y. T. et al. Mapping protein-specific micro-environments in live cells by fluorescence lifetime imaging of a hybrid genetic-chemical molecular rotor tag. Chem. Commun. 48, 8694-8696, (2012).

\section{Acknowledgements}

AJB thanks the BBSRC for a David Philip's fellowship, and TDC thanks the BBSRC for funding. TJN thanks the BBSRC and New College for funding and O. Tkachenko, Georg Hochberg, J. Hopper, S. Chandler and S. Habash for gifts of GFP tagged proteins, E Fussner-Dupas for antibody-labelling support and B. Davis for discussion and use of instrumentation. The authors thank LE Kay for discussion.

\section{Author contributions}

TJN, AJB and TDC conceived and designed experiments, analysed data and co-wrote the manuscript. TJN performed experiments. 

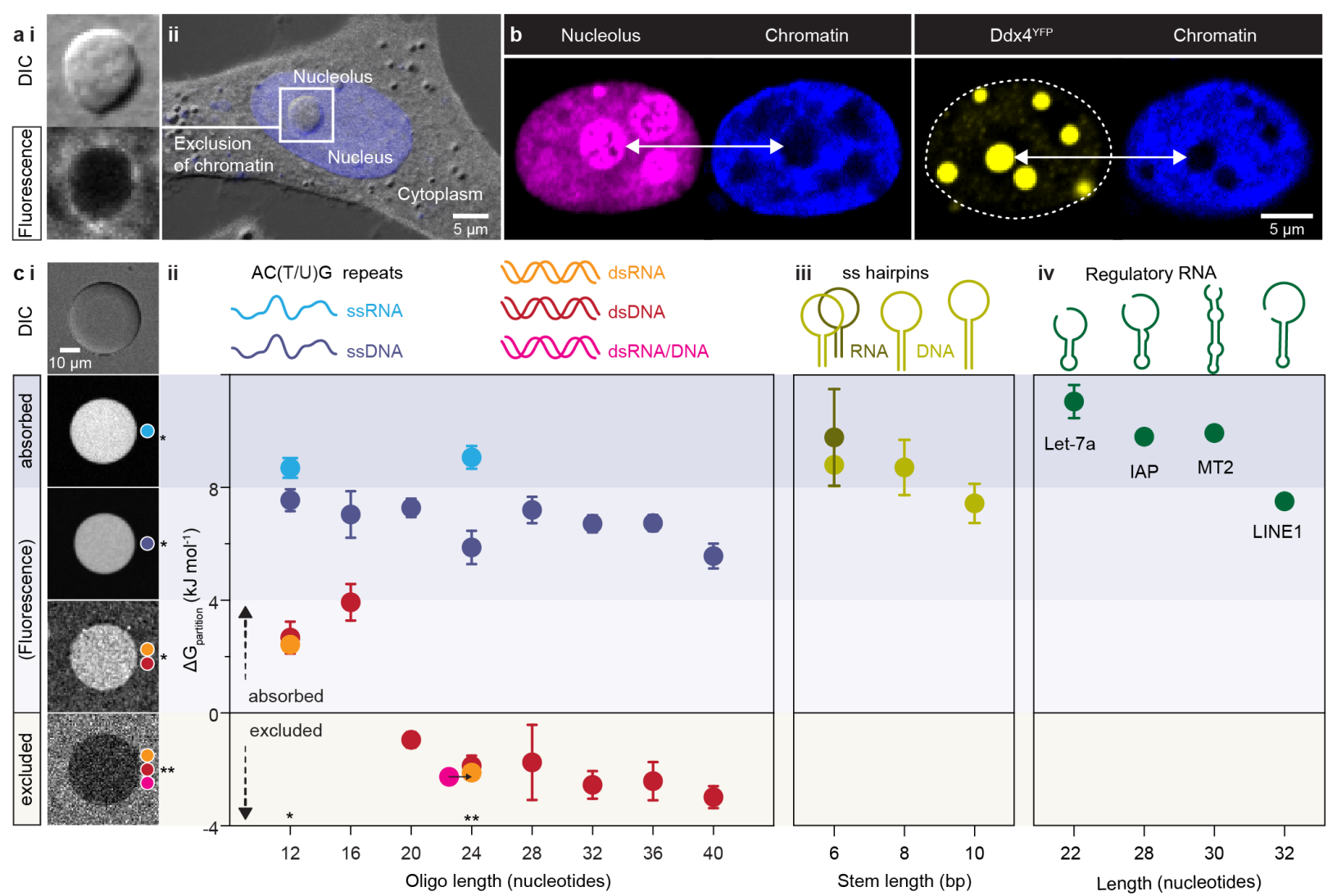

d $\quad$ GC $\square$ AU/T

Figure 1| Membraneless organelles selectively partition oligonucleotides. ai, Nucleoli of cultured cells are visible as dense, spherical droplets and exclude fluorescently-stained chromatin. (ii, Nucleolus from i shown in the context of the whole cell. b, Nucleoli, Ddx $4{ }^{\mathrm{YFP}}$ organelles $^{8}$ and chromatin visualised together in a HeLa cell nucleus. Both Nucleoli and $\mathrm{Ddx} 4{ }^{\mathrm{YFP}}$ organelles exclude chromatin. c, Ddx $4^{\mathrm{N} 1}$ organelles differentially partition nucleic acids in vitro. $\mathbf{i}$ and ii, Partitioning of a series of DNA and RNA oligonucleotides made of ACTG of ACUG repeats. Error bars show the standard deviation of multiple individual organelles $(>30)$ obtained over at least 2 independent sample preparations. Duplexes longer than 20 base pairs are predominantly excluded from $\mathrm{Ddx} 4^{\mathrm{N} 1}$ organelles, whereas shorter duplexes and single-stranded oligonucleotides are absorbed. Coloured circles and asterisks in $\mathbf{i}$ correspond to the nucleic acids in ii. DNA and RNA hairpins with either synthetic (iii) or physiological (iv) sequences are absorbed into $\mathrm{Ddx} 4^{\mathrm{N} 1}$ organelles. d, Nucleotide composition of sequences used in this study (Supplementary Table 1). 


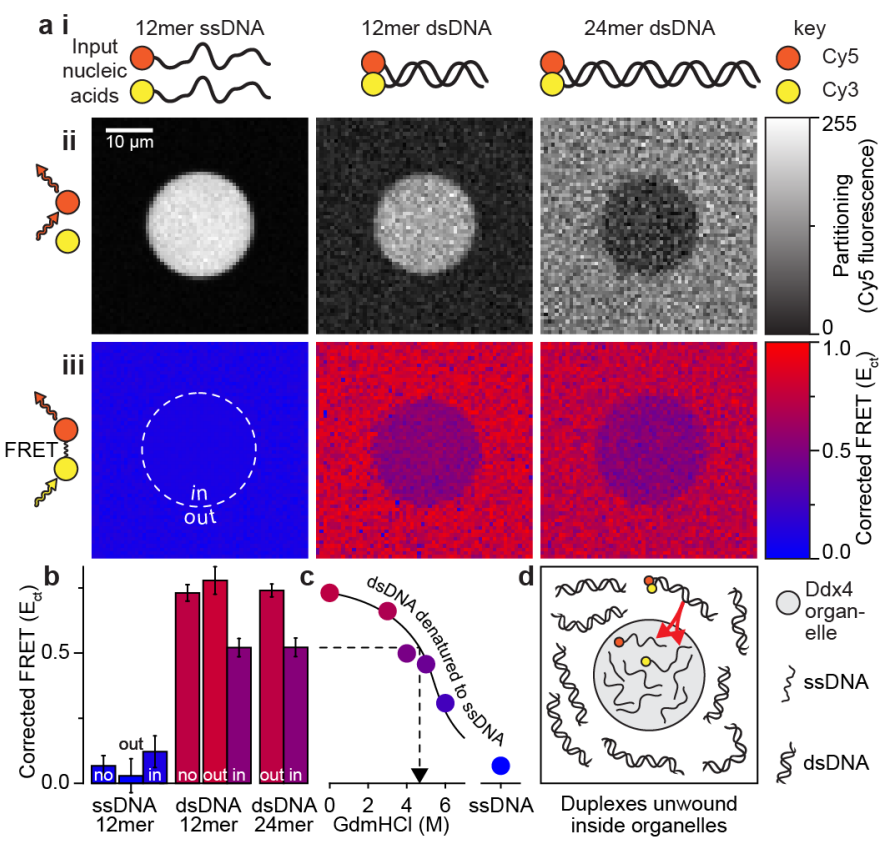

Figure 2| Ddx4 ${ }^{\mathrm{N} 1}$ organelles destabilise oligonucleotide duplexes. a, 12mer ssDNA and 12mer and 24mer dsDNA tagged with Cy3 (donor) and Cy5 (acceptor) fluorophores (i) were used to simultaneously measure nucleic acid partitioning (ii) and FRET (iii) inside and outside $\operatorname{Ddx} 4^{\mathrm{N} 1}$ organelles. b, Quantitation of the corrected FRET signals from inside and outside Ddx $4^{\mathrm{N} 1}$ organelles. Error bars show the standard deviation from at least 30 individual organelles, measured over at least 2 independent sample preparations. c, Chemical denaturation of the 12mer FRET-pair dsDNA by GdmHCl determined using a fluorimeter assay. d, Schematic depiction of the dissociation of nucleic acid duplexes upon entering $\mathrm{Ddx} 4^{\mathrm{N} 1}$ organelles. 

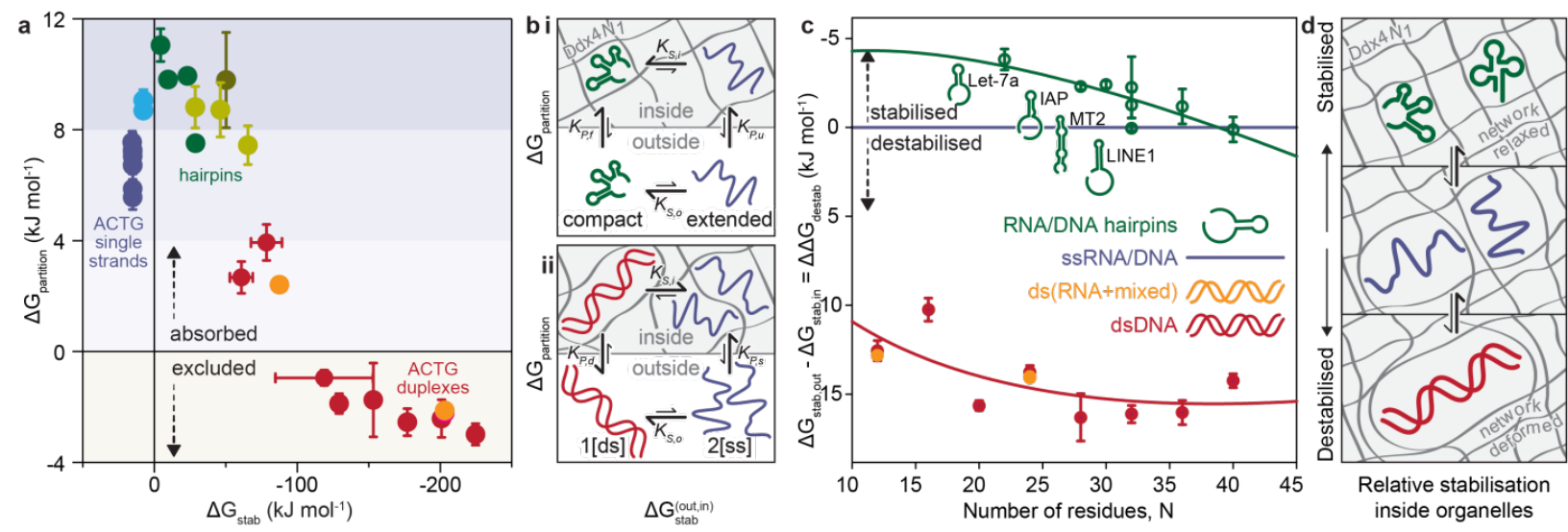

Figure $3 \mid \mathrm{Ddx}^{\mathrm{N} 1}$ organelle partitioning depends on the stability of the nucleic acid structure. a, $\mathrm{Ddx} 4^{\mathrm{N} 1}$ organelle partitioning for all the sequences shown in Fig. 1c as a function of stability. Colour scheme and y-error bars as in Fig. 1c. x-error bars are the standard error of a linear fit to experimentally derived $\Delta \mathrm{G}_{\text {stab }}$ (see Supplementary Material). b, The partitioning data can be interpreted using equilibrium schemes. In the case of single-stranded oligonucleotides, the stabilisation corresponds to folding (i), and in the case of double-stranded oligonucleotides, the stabilisation corresponds to melting (ii) c, Using the measurement of the partition free energy of the double-stranded DNA and the corresponding single-stranded DNAs together with the total concentration and the stability outside of the organelle, it is possible to calculate the stability inside the organelle, and hence the change in stability (red, bii, Supplementary Fig. 3c). In a similar way, the change in stability for the structured RNA and DNA hairpins can be estimated (green, bi, Supplementary Fig. 3c). Errors are the same as in Fig 1c. d, The data suggest that both extended and rigid nucleic acid duplexes are destabilised in the organelle interior, favouring instead compact, single chains that will minimally distort the interior of the underlying droplets. 


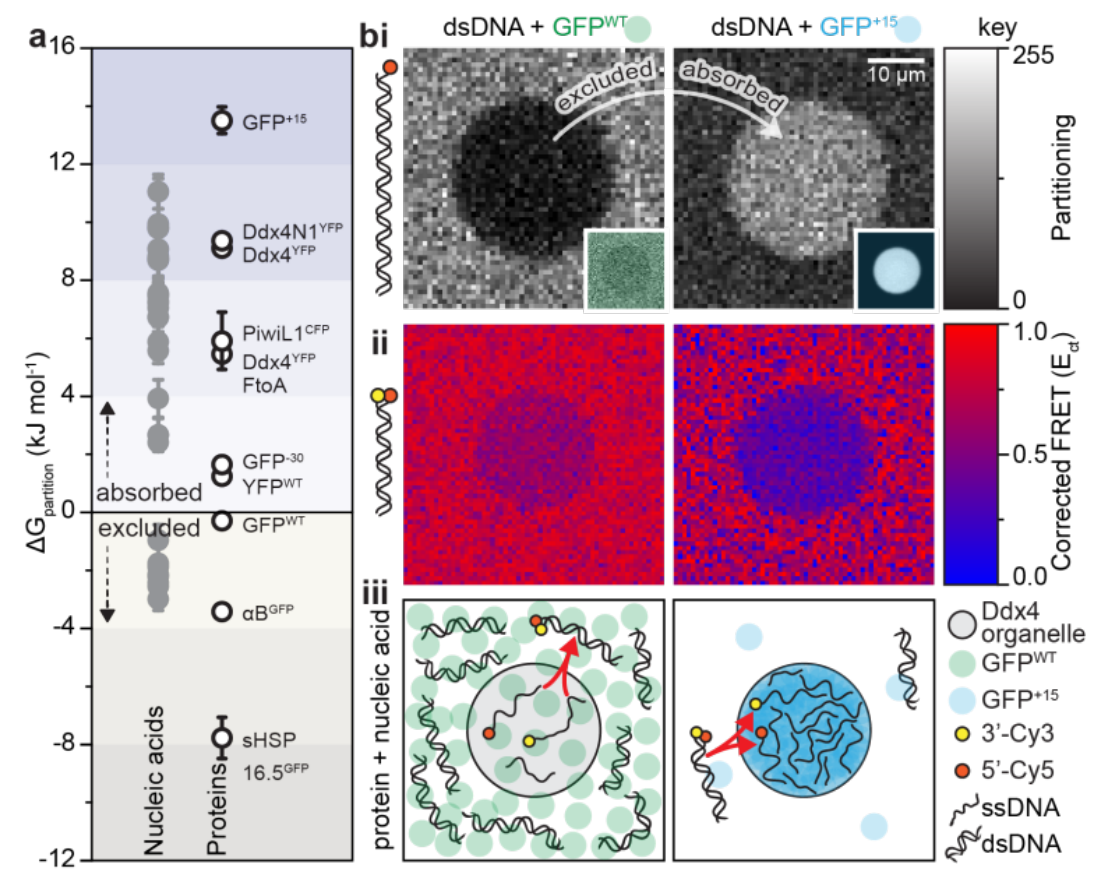

Figure $4 \mid \mathrm{Ddx}^{\mathrm{N1}}$ organelles differentially partition proteins, which in turn can act as importers for dsDNA. a, Proteins (white-filled circles) show a wider range of partitioning than nucleic acids (grey). Error bars show the standard deviation of measurements from at least 30 organelles from at least 2 independent samples. The data can be quantitatively explained from sequence information alone (Supplementary Fig. 4 bi, ii). b i, 40 mer dsDNA is excluded from Ddx $4^{\mathrm{N} 1}$ organelles in the presence of $\mathrm{GFP}^{\mathrm{WT}}$, but absorbed in the presence of $\mathrm{GFP}^{+15}$. ii, FRET images of $24 \mathrm{mer}$ dsDNA in the presence of $\mathrm{GFP}^{\mathrm{WT}}$ and $\mathrm{GFP}^{+15}$. In both cases, FRET is reduced inside the $\mathrm{Ddx} 4^{\mathrm{N} 1}$ organelle. iii, Schematic depiction showing the exclusion of long nucleic acid duplexes in the presence of $\mathrm{GFP}^{\mathrm{WT}}$, and the absorption and dissociation to single strands of long duplexes in the presence of $\mathrm{GFP}^{+15}$. 


\title{
Supplementary Information
}

\section{Membraneless organelles can melt nucleic acid duplexes and act as biomolecular}

\author{
Authors: Timothy J Nott ${ }^{1 *}$, Timothy D Craggs ${ }^{2}$, Andrew J Baldwin ${ }^{{ }^{*}}$ \\ 1. Physical and Theoretical Chemistry, University of Oxford, UK \\ 2. DNA-Protein Interactions Unit, School of Biochemistry, University of Bristol, UK \\ *correspondence to be addressed to andrew.baldwin@chem.ox.ac.uk and \\ timothy.nott@chem.ox.ac.uk
}

Supplementary Information:

Detailed Methods

Supplementary Figures 1-4

Supplementary Tables 1-8

Supplementary References (32-38) 


\section{Detailed Methods}

\section{Imaging fixed HeLa cells}

HeLa cells expressing Ddx4 $4^{\mathrm{YFP}}$ and Ddx4 $4^{\mathrm{YFP}}$ FtoA were grown on $25 \mathrm{~mm}$ glass coverslips, and fixed with $4 \%$ paraformaldehyde (PFA) in phosphate buffered saline (PBS), for 5 minutes at $37^{\circ} \mathrm{C}$. Cells were then washed three times with PBS to remove excess PFA. Next, cells were permeabilised with $0.5 \%$ TritonX100 (in PBS) for 10 minutes, and again washed three times with PBS. Nuclei were visualized with Hoechst or DAPI stain. Cells were washed a further two times with PBS to remove excess Hoechst/DAPI stain and imaged using an Olympus IX81 inverted microscope with a 60x (NA 1.3) silicon immersion objective. Hoechst/DAPI dye was excited with a $405 \mathrm{~nm}$ laser and YFP was excited with a $515 \mathrm{~nm}$ laser. Hoechst/DAPI and YFP fluorescence were detected at 461 and $527 \mathrm{~nm}$ respectively. Differential interference contrast (DIC) images were collected using illumination from the $405 \mathrm{~nm}$ laser.

\section{Immunofluorescence}

For immunofluorescence experiments, HeLa cells expressing $\mathrm{Ddx} 4^{\mathrm{YFP}}$ were grown on $25 \mathrm{~mm}$ diameter \#1.5 glass coverslips (Warner Instruments). The fixation and permeabilisation of samples was performed as above. Cells were then blocked with goat serum (5\% in PBS) for one hour at room temperature before antibody staining. Primary antibodies were diluted to between 1:10 and 1:100 (in PBS containing 5\% goat serum) before use. Nucleoli were labelled using mouse B23 (Santa Cruz sc-56622) antibodies. Following incubation at $4{ }^{\circ} \mathrm{C}$ overnight, excess primary antibodies were removed by washing the cells three times with PBS (five minutes per wash).

Cells were then incubated with Cy3 goat anti-mouse secondary antibodies (diluted 1:400) for 1 hour at room temperature. Excess secondary antibodies were removed by washing with PBS, as above. Nuclei were visualized with DAPI stain. Coverslips were then mounted on microscope slides using glycerol $/ n$ propyl gallate mounting medium, sealed with nail varnish, and imaged using an Olympus IX81 inverted microscope equipped with a 60x (NA 1.3) silicon immersion objective. DAPI, YFP and Cy3 and dyes were excited with $405 \mathrm{~nm}, 515 \mathrm{~nm}$ and $559 \mathrm{~nm}$ lasers, respectively. 26 Z-slices (0.4 $\mu \mathrm{m}$ spacing, $12.5 \mu$ sixel $^{-1}$ scanning speed, 12 bit depth) were captured for each channel.

\section{Determination of fluorescence lifetime}

Fluorescence lifetime measurements were made using a Becker \& Hickl FLIM system attached to an Olympus IX81 microscope, equipped with a 40x (1.3 N.A.) oil UPlan FLN objective. Fluorescence excitation was produced with a pulsed $488 \mathrm{~nm}$ laser, operating at $80 \mathrm{MHz}$. Analysis was performed using SPCImage software. Samples contained either GFP ${ }^{W T}$ (superfolder GFP ${ }^{29,32}$ ) or 5'-Cy3 ssDNA (12mer), and were prepared as for partitioning experiments, described below.

\section{Changes in quantum yield in Cy3 and Cy5 dyes}


Given that the dielectric and viscosity of the droplet interior differs significantly from its dilute aqueous surroundings, one might expect a difference in the quantum yield (brightness) of fluorophores in the two phases. Such a change would amount to a systematic dye-dependent offset of the 'zero point' in partitioning data derived from intensity ratios. Measuring quantum yield, or relative quantum yield using a confocal microscopy is not straightforward, due to the need to simultaneously measure absorption and fluorescence emission. The quantum yields and fluorescent life times for Cy3 have been determined in environments that cover a wide range of dielectrics and viscosities, and are found to be positively correlated. ${ }^{33,34}$ (Supplementary Fig. 1f), meaning that measured values can be used to put limits on what the change in quantum yield inside and outside organelle droplets can be. Using fluorescence-lifetime imaging microscopy (FLIM), we observed a $7 \%$ increase in lifetime of Cy3 conjugated to ssDNA upon entering the organelles (1518 \pm 46 ps inside, $1406 \pm 77$ ps outside, Supplementary Fig. 1e), amounting to an estimated $14 \%$ increase in quantum yield. Such a correction amounts to a subtract of $0.45 \mathrm{~kJ} \mathrm{~mol}^{-1}$ from all reported nucleic acid partition free energies (Fig 1). This would, for these data, make double stranded DNA slightly more excluded and single stranded DNA slight less absorbed than apparent from the raw data. However, as partition energies are typically more than 10 times larger than this value, we consider this correction here to be essentially negligible. Due the approximate nature of the calibration, the reported values are not directly corrected.

\section{Changes in quantum yield in fluorescent proteins}

For fluorescent proteins, the quantum yield has been shown to be independent of both solvent polarity and viscosity ${ }^{26,27}$, a finding which has facilitated their widespread application in the field of cellular biology. Interestingly, however, the fluorescence lifetimes do vary with solution conditions, but changes are mutually self-compensatory such that the quantum yield does not change. Our measured GFPWT lifetime changes ( $2130 \pm 37$ ps inside, $2334 \pm 36$ ps outside) here are consistent with going from water to a $60 \%$ glycerol solution with a 16 fold increase in viscosity ${ }^{27}$ (Supplementary Fig. 1e,f).

If the fluorescent proteins were unfolding in the interior of the droplets, then we could be systematically underestimating the partition free energies. The fluorescent proteins studied have a range of stabilities with respect to denaturant unfolding. The most stable isolated fluorescent protein, the 'superfolding' GFP ${ }^{\text {WT } 29,32}$, was found to have the lowest partition free energy, and the least stable fluorescent proteins, $\mathrm{GFP}^{+15}$ and $\mathrm{GFP}^{-30}$ were found to be the most absorbed. These results are in the opposite direction to that is expected from denaturant unfolding.

If we assume that the interior of the droplets behaves like $4 \mathrm{M} \mathrm{GdmHCl}$, then GFP ${ }^{\mathrm{WT}}$ would be $90 \%$ folded $^{29}$ leading to a correction of +0.3 in its $\Delta G_{\text {part }}$ and $\mathrm{GFP}^{-30}$ would be expected to be $30 \%$ folded $^{29}$, leading to a shift of $+3 \mathrm{~kJ} \mathrm{~mol}^{-1}$ in $\Delta G_{\text {part }}$. Both corrections are small when compared to the observed magnitude of $\Delta G_{\text {part }}$ in our assays.

\section{Theoretical determination of oligonucleotide stability $\left(\Delta G_{\text {stab }}\right)$}


Oligonucleotide stability $\left(\Delta G_{\text {stab }}\right.$ ) was predicted using the calculator UNAFold ${ }^{35}$ with $1 \mu \mathrm{M}$ oligo (selecting DNA or RNA as appropriate), $150 \mathrm{mM} \mathrm{NaCl}$ at $25^{\circ} \mathrm{C}$ (table S1). The stabilities of the $12 \mathrm{mer}, 16 \mathrm{mer}$ and 20 mer ACTG duplexes were independently verified by experimental measurement in-house.

\section{Experimental determination of oligonucleotide stability $\left(\Delta G_{\text {stab }}\right)$}

The change in hyperchromicity associated with duplex annealing was normalised to go from 1 at low temperatures (fully duplex) and 0 at high temperatures (no duplex), and taken to be mole fraction of duplex $F=2[d s] / s s_{\text {tot }}$ where $[d s]$ and $s s_{\text {tot }}$ are the double stranded concentration and total concentration of all single chained oligonucleotides in the system. Noting that $s s_{t o t}=2[d s]+[s s]$, where [ss] is the total concentration of free single stranded DNA, the mole fraction $\mathrm{F}$ can be converted into a free energy:

$$
\Delta G=-R T \ln \frac{[d s]}{[s s / 2]^{2}}=-R T \ln \frac{2 F}{s s_{t o t}(1-F)^{2}}
$$

which varies with temperature as $\Delta G=\Delta H-T \Delta S$. Rearranging and solving for $F$ gives its functional variance with temperature:

$F=1+e^{(\Delta H / T-\Delta S) / R} / S S_{t o t}+\sqrt{\left(1+e^{(\Delta H / T-\Delta S) / R} / S S_{t o t}\right)^{2}-1}$

At the temperature midpoint, $T_{M}, F=0.5$ and so:

$$
\Delta G=\Delta H-T_{m} \Delta S=-R T_{m} \ln \frac{4}{s s_{\text {tot }}}
$$

A plot of $1 / T_{M}$ versus $\ln \left(4 / s S_{\text {tot }}\right)$ enables determination of $\Delta H$ and $\Delta S$. This method was applied to 12,16 and 20 mer duplex DNAs (Fig. 3a, x-error bars, Supplementary Fig. 3a, b). The experimentally derived values were in excellent accord with those calculated from the sequence alone ${ }^{35}$.

\section{Partitioning experiments $\left(\Delta G_{\text {part }}\right)$}

$\mathrm{Ddx} 4^{\mathrm{N} 1}$ membraneless organelle samples were prepared as squashed drops as previously described ${ }^{8}$. Briefly, $1.35 \mu \mathrm{L}$ of Ddx4 $4^{\mathrm{N} 1}$ (325 $\mu \mathrm{M}$ in GF buffer; $20 \mathrm{mM}$ Tris $\mathrm{pH} 8.0$ at RT, $300 \mathrm{mM} \mathrm{NaCl}, 5 \mathrm{mM}$ TCEP) was mixed 1:1 with an oligo or fluorescent protein sample on a round $22 \mathrm{~mm}$ siliconised coverslip (Hampton Research) and equilibrated as a hanging drop over a well solution of $20 \mathrm{mM}$ Tris pH 8 at RT, $150 \mathrm{mM}$ $\mathrm{NaCl}$ for 15 minutes (30 minutes for ternary mixtures also containing GFP). The well was sealed with Vaseline. The coverslip was removed after the equilibration period, excess Vaseline removed with a 200 uL pipette tip, and the droplet dispersed onto a microscope slide (Fisherbrand Superfrost catalogue \#12550-123).

In all cases the final concentration of Cy5- and/or Cy3-labelled oligonucleotides in the hanging droplet was $1 \mu \mathrm{M}(0.5 \mu \mathrm{M}$ for ternary mixtures also containing GFPs (Fig. 4b, Supplementary Fig. 4a)). For example, the dsDNA ACTG FRET sample contained the sense strand ([Cy5]ACTGACTGACTG) at $1 \mu \mathrm{M}$ and the antisense strand (CAGTCAGTCAGT[Cy3]) at $1 \mu \mathrm{M}$. The protein partitioning experiments were performed in an identical fashion. The final concentrations in the hanging drops are summarised in table S2 together with properties of the sequence. 


\section{Microscopy and image analysis}

Image analysis was performed using $\mathrm{Fiji}^{36}$. Quantitation of partitioning was achieved by selecting circular regions of interest (ROIs) comprising 5 individual $\mathrm{Ddx} 4^{\mathrm{N} 1}$ organelles (and 5 equally sized regions of adjacent dilute phase) for three fields of view (FOV) per sample with two independent samples per experiment. The z-stack for each ROI was cropped to 5 slices, centred on the middle of the sample (Supplementary Fig. 2). The sum of the fluorescence from each ROI was divided by its volume to normalise for ROI size. The normalised fluorescence from $\mathrm{Ddx} 4^{\mathrm{N} 1}$ protein-only control samples was used to baseline-correct samples containing fluorescent material. The ratio of the baseline-subtracted sum/vol for each organelle and nearest adjacent region of dilute phase was taken, and converted into a free energy via:

$\Delta G_{\text {part }}=-R T \ln ([$ in $] /[$ out $])$

where [in] and [out] are the total concentrations of oligonucleotides inside and outside the organelles. The reported values are the mean and standard deviation of the partitioning of 30 organelles ( 5 per FOV, 3 FOVs per sample, 2 samples) per fluorescent oligo or protein.

\section{Topological frustration of nucleic acids inside membraneless organelles}

The per-residue thermodynamic quantities $\Delta G_{\text {part }} / N$ and $\Delta G_{\text {destab }} / N$ were observed to decrease as a function of length, suggesting that the contribution per residue decreases as a function of sequence length. This is to be expected where there is topological frustration in the system ${ }^{25}$. When a single strand is dissolved inside an organelle, each residue will make many weak interactions with itself and solvent. Individual residues in shorter oligonucleotides will have the freedom to orientate themselves most favourably, whereas for longer oligonucleotides this will be more challenging, energetically speaking, if the mobility of the molecule is restricted. This scaling, where the free energy per residue decreases as a function of length in this way can be considered a form of topological frustration. In general terms, a reduced description of the free energy can be given in terms of factors that depend on its volume, and those that depend on its surface area. The former are proportional to the radius cubed, and so depends on $\mathrm{N}$. The latter depends on the radius squared, and so depends on $\mathrm{N}^{2 / 3}$.

$$
\Delta G=\text { volume }+ \text { surface }=a N+b N^{2 / 3}
$$

The free energy per residue is then expected to have a particular variation with length:

$$
\frac{\Delta G}{N}=a+\frac{b}{N^{1 / 3}}
$$

This is precisely the scaling seen in both DNA destabilisation (Fig. 3c, solid lines, Supplementary Fig. 3c), and intrinsic single and double stranded DNA partitioning. The fitting parameters obtained are 
summarised in table S5. These results collectively show that individual bases within longer oligonucleotides contribute less than individual bases within shorter oligonucleotides, suggesting that the liquid drops are more able to restructure and stabilise shorter molecules than longer ones.

\section{Duplex destabilisation by Ddx4 $4^{\mathrm{N} 1}$ organelles using FRET-pair nucleic acids}

A series of FRET samples based on the dsDNA or ssDNA 12mer ACTG oligonucleotides and 24mer dsDNA ACTG oligonucleotides were used to investigate whether $\mathrm{Ddx} 4^{\mathrm{N} 1}$ organelles destabilised nucleic acid duplexes. Measurements were made using confocal microscopy. The differently labelled oligonucleotides used in the study are listed in table S6. The correction factors measured in control measurements for a FRET calculation are shown in table S7, along with the final results. To validate these results, FRET experiments were repeated in a fluorimeter in the presence of increasing amounts of the denaturant guanadinium hydrochloride $(\mathrm{GdmHCl})$.

\section{Measurement of FRET by confocal microscopy}

In each FRET experiment involving 12mer ssDNA and 12mer and 24mer dsDNA samples, 3 fluorescence images were recorded per z-slice. This produced three z-stacks corresponding to the following absorption/emission schemes:

i. $\quad D D_{o b s}=$ observed donor emission after donor excitation.

ii. $D A_{o b s}=$ observed acceptor emission after donor excitation (FRET).

iii. $\quad A A_{\text {obs }}=$ observed acceptor emission after acceptor excitation.

In FRET experiments containing only Cy3 and Cy5 fluorophores, the donor fluorophore (Cy3) was excited using a $514 \mathrm{~nm}$ laser and the acceptor fluorophore (Cy5) was excited using a $633 \mathrm{~nm}$ laser. Donor emission was collected between 555 and $620 \mathrm{~nm}$, whilst acceptor emission was collected between 650 and $750 \mathrm{~nm}$.

In FRET experiments involving 24mer ACTG dsDNA in the presence of GFP'T or GFP ${ }^{+15}$ : GFPs were excited using a $488 \mathrm{~nm}$ maser, Cy3 was excited using a $543 \mathrm{~nm}$ laser and Cy5 was excited using a $633 \mathrm{~nm}$ laser. Emission bands for Cy3 and Cy5 as above.

The overlap of acceptor and donor emission and excitation bands means that the observed emission values need to be corrected to obtain a FRET measurement. To account for this, equivalent emission intensities as above were recorded using samples that contained only donor $\left(D D_{\text {donor, }} D A_{\text {donor }}\right)$ or acceptor fluorophores $\left(D A_{\text {accept }} A A_{\text {accept }}\right.$ ) with identical hardware parameters (i.e. laser intensity, detector sensitivity and emission bandwidth). Image processing and analysis was performed as described above. The volume-normalised and base-lined fluorescence intensities for equivalent ROIs in each of the $D D_{\text {obs, }}$ $D A_{\text {obs }}, A A_{\text {obs, }} D D_{\text {donor, }} D A_{\text {donor, }} D A_{\text {accept }}$ and $A A_{\text {accept }}$ image stacks were recorded and used for subsequent calculations.

The corrected FRET, $E_{C T}$, is then obtained from the following: 
where the correction terms:

$$
E_{c t}=\frac{D A}{D A+D D}=\frac{D A_{o b s}-\alpha \cdot D D_{o b s}-\beta \cdot A A_{o b s}}{D D_{o b s}+\left(D A_{o b s}-\alpha \cdot D D_{o b s}-\beta \cdot A A_{o b s}\right)}
$$

$$
\alpha=\frac{D A_{\text {donor }}}{D D_{\text {donor }}} \quad \text { and } \quad \beta=\frac{D A_{\text {accept }}}{A A_{\text {accept }}}
$$

Measurements were performed on single stranded and double stranded $12 \mathrm{mers}$, inside and outside organelles, and in dilute solution where no organelles were present. The correction factors and FRET measurements are summarised in table S7. FRET was calculated on a per-ROI (organelle or region of dilutes phase) basis. The reported FRET values are the mean and standard deviation of the corrected FRET signals of 30 organelles or equivalently sized regions of dilute phase ( 5 per field of view (FOV), 3 FOVs per sample, 2 samples).

For the FRET images in Fig. 2aiii and Fig. 4bii, representative organelles were selected, and the frame cropped in the xy plane to include some of the surrounding dilute region. Next, the z-stack was cropped to the 5 slices at the middle of the sample. The same procedure was applied to each of the three fluorescence z-stacks recorded in the FRET experiment. A z-projection of the sum of intensities was next produced for each image stack, and a corrected FRET $\left(E_{c t}\right)$ composite image was generated according to the $E_{c t}$ equation above, with the appropriate z-projection images substituted for the $D D_{o b s,} D A_{o b s}$ and

$A A_{\text {obs }}$ terms. The average of the inside and outside organelle correction factors ( $\alpha$ and $\beta$, Supplementary Table 7, Supplementary Fig. 4c) were used to scale the whole images. The mean grey values obtained for the organelle region of the processed images were subsequently linearly scaled to those obtained after the full analysis of many organelles, fields of view and samples so that the images gave a representative visualisation of the data.

\section{Measurement of FRET by fluorimeter}

For samples not containing $\mathrm{GdmHCl}, \mathrm{Cy} 3$ (donor) and Cy5 (acceptor) excitation was achieved at 514 and $633 \mathrm{~nm}$, respectively, each with slit widths of $7.5 \mathrm{~nm}$. Spectra (500 and $800 \mathrm{~nm}$ ) were collected with a scan rate of $240 \mathrm{~nm} \mathrm{~min}$. For samples containing $\mathrm{GdmHCl}, \mathrm{Cy} 3$ (donor) and Cy5 (acceptor) excitation was achieved at 514 and $633 \mathrm{~nm}$, respectively, each with slit widths of $5 \mathrm{~nm}$. Spectra (500 to $800 \mathrm{~nm}$ ) were collected with a scan rate of $120 \mathrm{~nm} \mathrm{~min}^{-1}$.

The data were quantified using the integrative ratio $\mathrm{A}\left(R_{A}\right)$ method $^{37}$. The spectrum (intensity values are a function of emission frequency $\omega$ ) was recorded after donor excitation for samples containing donor only $f((D) \omega)_{\text {donor }}$ and a mixture of donor and acceptor $f((D) \omega)_{\text {mix }}$, and after acceptor excitation for the mixture $f((A) \omega)_{\text {mix. }}$. The ratios were then calculated as follows:

$$
R_{A}=\frac{\sum_{\omega} f(D, \omega)_{\text {mix }}-N f(D, \omega)_{d o n o r}}{\sum_{\omega} f(A, \omega)_{\text {mix }}} \text { where } N=\frac{f(D, \max )_{\text {mix }}}{f(D, \max )_{d o n o r}}
$$


Where max is the value of $\omega$ where the donor emission is a maximum. The values of $R_{A}$ were found to decrease as $\mathrm{GdmHCl}$ concentration was increased in the double stranded DNA samples, indicating destabiliation of the double strand with denaturant (summarised in table $S 8$ ). $R_{A}$ data was linearly scaled to the corrected FRET values obtained from equivalent samples using confocal microscopy, with ssDNA and dsDNA (no denaturant) as lower and upper bounds, respectively (Fig. 2c). 


\section{Thermodynamic analysis of combined partitioning $\left(\Delta G_{\text {part }}\right)$ and changes in structure $\left(\Delta G_{\text {stab }}\right)$}

\section{Analysis of single stranded oligonucleotide destabilisation}

The partitioning data of single stranded nucleic acids was analysed according to the following thermodynamic square (Fig. 3bi), where folding and unfolded forms are distinguished by $f$ and $u$ :

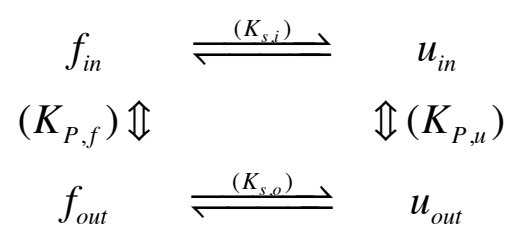

Which is defined by four equilibrium coefficients

$$
K_{S, o}=\frac{f_{\text {out }}}{u_{\text {out }}}, \quad K_{S, i}=\frac{f_{\text {in }}}{u_{\text {in }}}, \quad K_{P, f}=\frac{f_{\text {out }}}{f_{\text {in }}}, \quad K_{P, u}=\frac{u_{\text {out }}}{u_{\text {in }}}
$$

denoting the stability outside and inside the organelle $\left(K_{S, o}\right.$ and $\left.K_{S, i}\right)$ and the partition coefficient for folded and unfolded single stranded oligonucleotides $\left(K_{P, f}\right.$ and $\left.K_{P, u}\right)$. As before, due to the square geometry of the scheme:

$$
K_{S, o} K_{P, u}=K_{S, i} K_{P, f}
$$

The total concentration of oligonucleotide molecules is given by $s s_{\text {tot }}=f_{\text {out }}+f_{\text {in }}+u_{\text {out }}+u_{\text {in }}$ If we substitute in equilibrium constants we solve for $u_{\text {out }}$ :

$$
u_{\text {out }}=\frac{K_{P, u} K_{P, f} s s_{\text {tot }}}{\left(K_{P, f}+1\right) K_{P, u} K_{S, o}+\left(K_{P, u}+1\right) K_{P, f}}
$$

Our experimental observables are total concentration, stability of the DNA outside of the organelles, and the total partition coefficient are given by:

$$
\Delta G_{\text {stab }}=-R T \ln \frac{f_{\text {out }}}{u_{\text {out }}}, \quad K_{P}^{u}=\frac{u_{\text {in }}}{u_{\text {out }}}, \quad K_{P}^{\text {obs }}=\frac{f_{\text {in }}+u_{\text {in }}}{f_{\text {out }}+u_{\text {out }}}
$$

Where in the case of an unstructured single stranded oligonucleotide, $\Delta G_{\text {part }}=-R T \ln K_{P}{ }^{u}$, and for a structured single stranded oligonucleotide $\Delta G_{\text {part }}=-R T \ln K_{P}^{o b s}$. These can be manipulated to return to our original definitions:

$$
\begin{aligned}
K_{S, o} & =\exp \left(-\Delta G_{s t a b} / R T\right) \\
u_{\text {out }} & =\frac{s s_{t o t}}{\left(1+K_{P}^{o b s}\right)\left(1+K_{S, o}\right)} \\
K_{P, u} & =\frac{1}{K_{P}^{u}} \\
K_{P, f} & =\frac{K_{S, o}}{K_{P}^{o b s}\left(K_{S, o}+1\right)-K_{P}^{u}} \\
K_{S, i} & =\frac{K_{S, o} K_{P, u}}{K_{P, f}}
\end{aligned}
$$


Finally, we define a destabilisation energy, the difference in free energy of DNA association inside and outside the organelles (Fig. 3c, hairpin data):

$$
\begin{aligned}
\Delta \Delta G_{\text {destab }} & =\Delta G_{\text {stab }}^{\text {out }}-\Delta G_{\text {stab }}^{\text {in }}=-R T \ln \frac{K_{S, o}}{K_{S, i}}=-R T \ln \frac{K_{P, f}}{K_{P, u}} \\
& =-R T \ln \frac{K_{S, o} K_{P}^{u}}{K_{P}^{\text {obs }}\left(K_{S, o}+1\right)-K_{P}^{u}}
\end{aligned}
$$

Overall, from an experimental measurement of $K_{P}^{U}, K_{P}^{o b s}, \Delta G_{\text {stab }}$ and knowledge of the total concentration $s s_{T o t}$, we can calculate the destabilisation energy for secondary structure in single stranded oligonucleotides.

\section{Analysis of double stranded nucleotide destabilisation}

The analysis of double stranded oligonucleotides destabilisation is similar to that for the single strands but not identical as when a single chain denatures, we are left with one molecule, whereas when a duplex melts we have two. The partitioning data of double stranded nucleic acids was analysed according to the following thermodynamic square (Fig. 3bii):

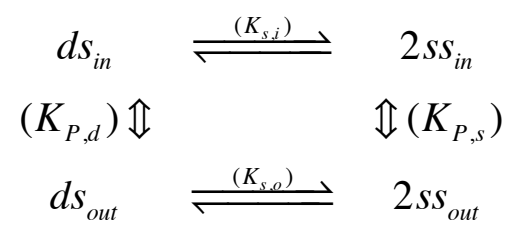

Which is defined by four equilibrium coefficients

$$
K_{S, o}=\frac{4 d s_{\text {out }}}{s s_{\text {out }}^{2}}, \quad K_{S, i}=\frac{4 d s_{\text {in }}}{s s_{\text {in }}^{2}}, \quad K_{P, d}=\frac{d s_{\text {out }}}{d s_{\text {in }}}, \quad K_{P, s}=\frac{s s_{\text {out }}}{s s_{\text {in }}}
$$

denoting the stability outside and inside the organelle $\left(K_{S, o}\right.$ and $\left.K_{S, i}\right)$ and the partition coefficient for double and single stranded oligonucleotides $\left(K_{P, d}\right.$ and $\left.K_{P, s}\right)$. The equilibrium constants are related to Gibb's free energies via $\Delta G=-R T \ln K$. As the geometry of the scheme is a square, any two sides are equivalent and so:

$$
K_{S, o} K_{P, s}^{2}=K_{S, i} K_{P, d}
$$

The total concentration of oligonucleotide molecules is given by $s s_{\text {tot }}=2 d s_{\text {out }}+2 d s_{\text {in }}+s s_{\text {out }}+s s_{\text {in }}$. If we substitute in equilibrium constants we can express the total concentration in terms of just $s s_{\text {out }}$.

$$
s s_{\text {tot }}=\frac{1}{2} s s_{\text {out }}^{2} K_{S, o}\left(1+\frac{1}{K_{P, d}}\right)+s s_{\text {out }}\left(1+\frac{1}{K_{P, S}}\right)
$$

Which can be solved:

$$
s s_{\text {out }}=-\left(1+\frac{1}{K_{P, s}}\right)+\sqrt{\left(1+\frac{1}{K_{P, s}}\right)^{2}+2 K_{S, o}\left(1+\frac{1}{K_{P, d}}\right) s s_{\text {tot }}} / K_{S, o}\left(1+\frac{1}{K_{P, d}}\right)
$$


Our experimental observables are total concentration, stability of the DNA outside of the organelles, and the total partition coefficient are given by:

$$
\Delta G_{\text {stab }}=-R T \ln \frac{4 d s_{\text {out }}}{s s_{\text {out }}^{2}}, \quad K_{P}^{s s}=\frac{s s_{\text {in }}}{s s_{\text {out }}}, \quad K_{P}^{d s}=\frac{2 d s_{\text {in }}+s s_{\text {in }}}{2 d s_{\text {out }}+s s_{\text {out }}}
$$

Where for a single stranded nucleotide $\Delta G_{\text {part }}=-R T \ln K_{P}^{S S}$, and for a double stranded, $\Delta G_{\text {part }}=-R T \ln K_{P}{ }^{D S}$. These can be manipulated to return to our original definitions:

$$
\begin{aligned}
K_{S, o} & =\exp \left(-\Delta G_{\text {stab }} / R T\right) \\
s s_{\text {out }} & =\left(-1+\sqrt{1+2 K_{S, o} s s_{\text {tot }} /\left(1+K_{P}^{d s}\right)}\right) / K_{S, o} \\
K_{P, s} & =\frac{1}{K_{P}^{s s}} \\
K_{P, d} & =\frac{s s_{\text {out }} K_{S, o}}{K_{P}^{d s}\left(s s_{\text {out }} K_{S, o}+2\right)-2 K_{P}^{s s}} \\
K_{S, i} & =\frac{K_{S, o} K_{P, s}^{2}}{K_{P, d}}
\end{aligned}
$$

Finally, we define a destabilisation energy, the difference in free energy of DNA association inside and outside the organelles:

$$
\Delta \Delta G_{\text {destab }}=\Delta G_{\text {stab }}^{\text {out }}-\Delta G_{\text {stab }}^{\text {in }}=-R T \ln \frac{K_{S, o}}{K_{S, i}}=-R T \ln \frac{K_{P, d}}{K_{P, s}^{2}}
$$

Overall, from experimental measures of $K_{P}^{S S}, K_{P}{ }^{D S}, \Delta G_{\text {stab }}$ and $s S_{\text {tot }}$ values, $\Delta G_{\text {destab }}$ for double stranded DNA can be directly calculated (Fig. 3c, double stranded DNA/RNA/hybrid data).

\section{Correlation between protein $\Delta G_{\text {part }}$ values and arginine/proline/tryptophan composition}

A statistical analysis was performed to determine if the $\Delta G_{\text {part }}$ values could be determined from properties of the protein sequences analysed. For the 11 sequences, the sequence length, molecular weight, oligomer mass, predicted pl, extinction coefficient, aromaticity, instability was determined together with both the number and proportion of each amino acid present in the sequence together with groupings of similar amino acids and secondary structure predictions. 56 individual statistical metrics were considered. Linear free energy relations were then constructed of the form:

$$
\Delta G_{\text {part }}^{\text {calc }}=\sum_{i} \kappa_{i} S_{i}
$$

Where $S$ is the statistical metric under consideration, and $\kappa$ is a proportionality constant. For each tested combination of statistical metrics considered, the constants $k$ were determined by minimising the least squares difference between the predicted $\Delta G_{\text {part }}^{\text {calc }}$ and the experimental $\Delta G_{\text {part }}$. Using a single statistic gave poor correlation between the calculated and experimental $\Delta G_{\text {part }}$ values $\left(R^{2}=0.557\right)$, using two 
statistics gives an $R^{2}$ of 0.84 , and three gives a maximum correlation of 0.94 . Moving from 3 values of $k$ to 4 resulted in correlations that were insufficiently improved to pass an F-test. We conclude therefore that we can well explain our data using three statistical measurements. The best correlation using 3 statistical metrics involves specifying the proline, arginine and tyrosine content as described in the text. 9 correlations were determined that were higher than 0.93 and generally reflect having a higher proportion of arginines and aromatic residue contact leads to higher $\Delta G_{\text {part }}$ values. Importantly, single physical descriptions of the chain such as $\mathrm{pl}$ and molecular weight were not found to correlate well with $\Delta G_{\text {part }}$ suggesting that the sequence composition the most important determinant for organelle trafficking. 


\section{Supplementay Figures}
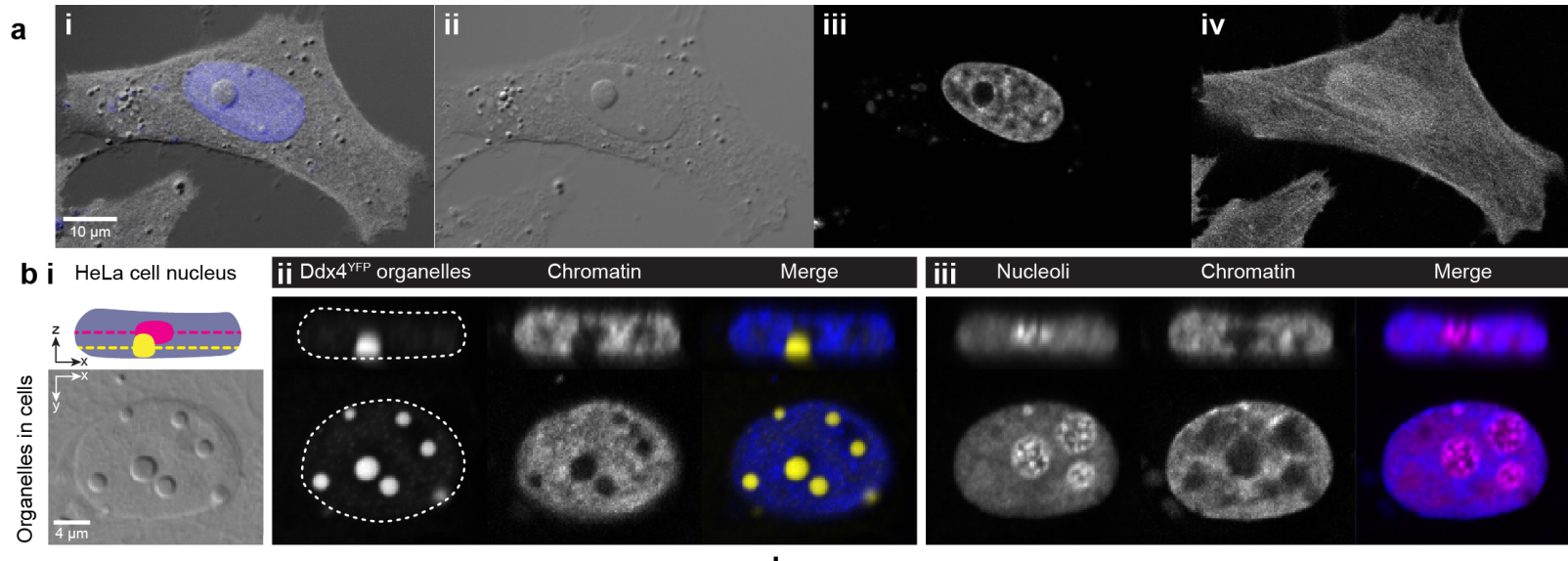
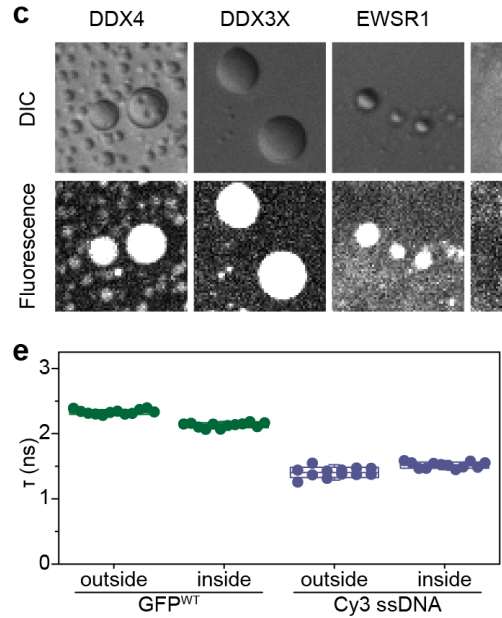

Chromatin
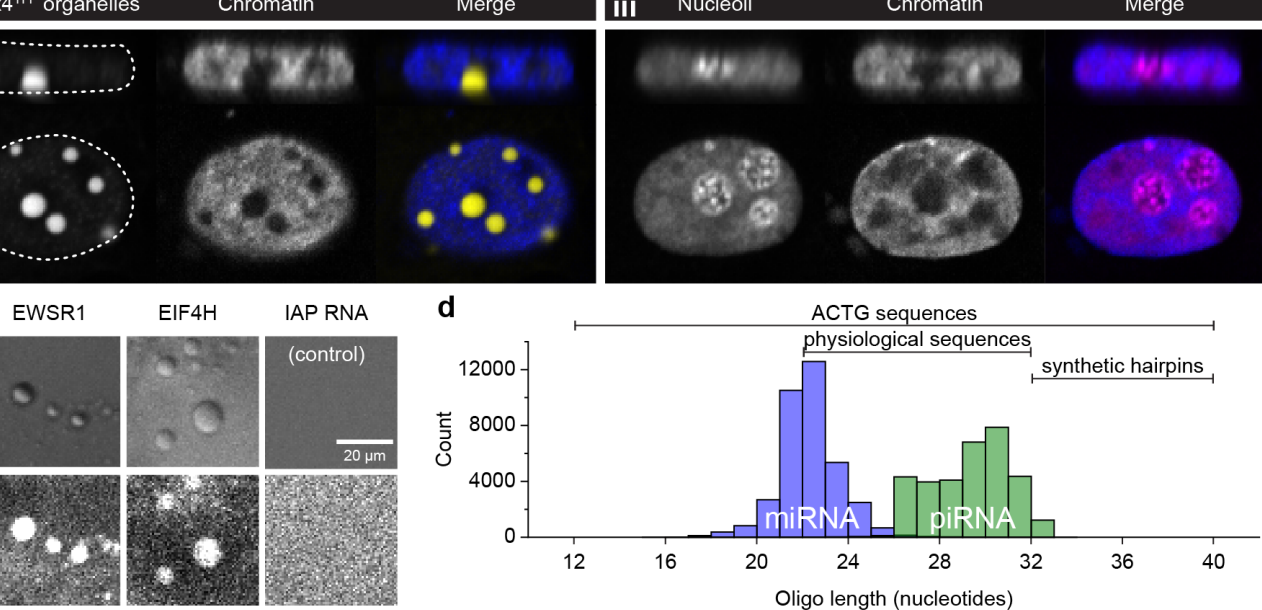

d
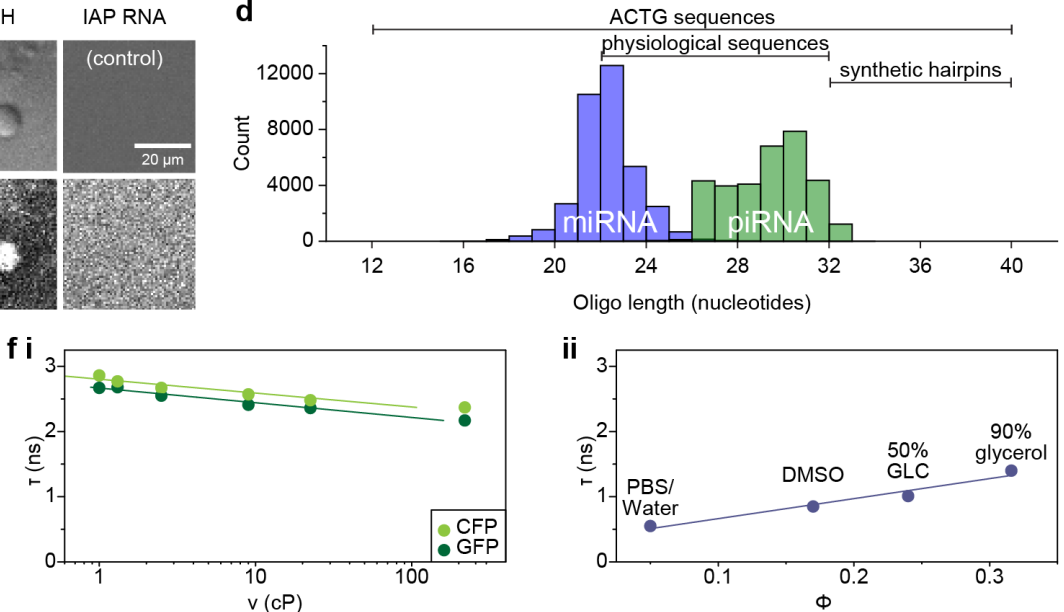

Supplementary Figure 1| a, Chromatin is excluded by the nucleolus and $\mathrm{Ddx} 4^{\mathrm{N} 1}$ organelles. Fluorescence and differential interference contrast (DIC) overlay (i), DIC (ii), chromatin stained with Hoechst dye (iii) and $\mathrm{Ddx} 4^{\mathrm{YFP}}$ FtoA (soluble variant of $\mathrm{Ddx} 4^{\mathrm{YFP}}$ dispersed in the cytoplasm and nucleus for additional contrast, iv). b, HeLa cell nucleus containing $\mathrm{Ddx} 4^{\mathrm{YFP}}$ organelles, counter stained to visualise chromatin and nucleoli. $i$, Schematic representation of the $x z$ view through the HeLa cell nucleus, showing Ddx4 ${ }^{\text {YFP }}$ organelles (yellow) and nucleoli (magenta). Dashed lines indicate, for the respective organelles, the zslice (i.e. $x y$ plane) shown in ii and iii. Both Ddx4 ${ }^{\mathrm{YFP}}$ organelles and nucleoli exclude bulk chromatin in the nucleus (ii and iii). c, DIC and confocal fluorescence images showing the partitioning of 5'-Cy5 28mer IAP RNA in organelles formed from a range of membraneless organelle-forming proteins in vitro. d, Distribution of the lengths of all miRNAs and all human piRNAs in the mirBASE and piRNAbank databases, respectively, compared to those used in this study (labelled horizontal bars). miRNA and piRNA are classes of small interfering RNAs involved in translational repression, mRNA degradation, transposon suppression and epigenetic regulation. e Fluorescence lifetime measurements both inside and outside of $\mathrm{Ddx}^{\mathrm{N1}}$ organelles for GFPWT and Cy3. $\mathbf{f} \mathbf{i}$, The correlation between the lifetime and solution viscosity for the fluorescent proteins CFP and GFP ${ }^{26,27}$. The change in GFP ${ }^{W T}$ lifetime in $\mathbf{e}$ is consistent with a $16 \mathrm{x}$ increase in viscosity. ii The correlation between the lifetime and quantum yield for 
Cy3. Changes in the lifetime of Cy3 between the inside and outside of organelles suggests a $20 \%$ change in quantum yield. This change suggests any correction to $\Delta G_{\text {part }}$ values (Fig 1 ) is small when compared to the trends observed ${ }^{33,34,38}$. Changes in the lifetime of the fluorescent proteins is not expected to correlate with changes in the quantum yield ${ }^{26,27}$. 


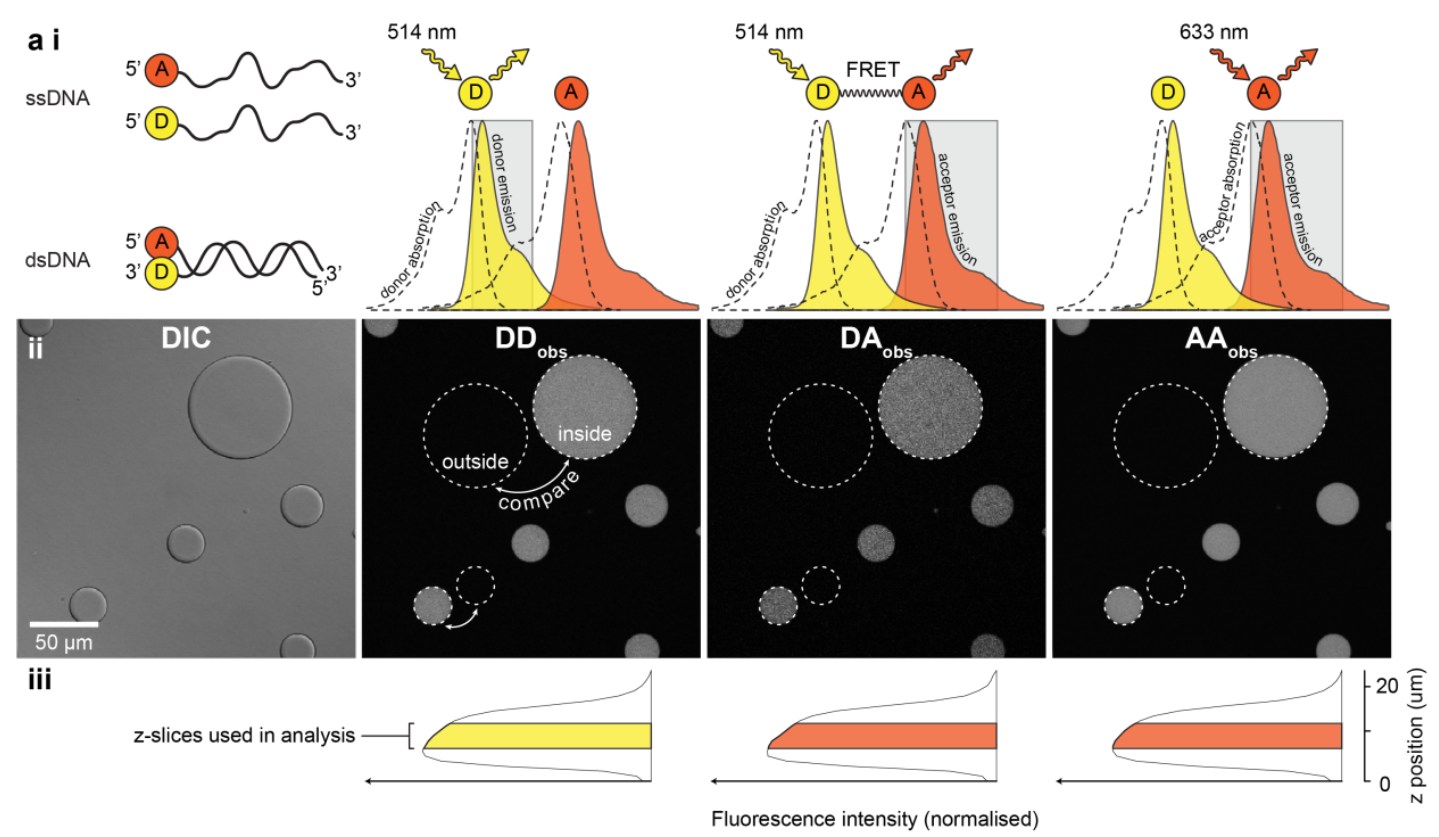

Supplementary Figure 2| ai, Schematic depiction of fluorescently labelled single and double-stranded ACTG DNAs used in FRET experiments. Cy3 (Donor, D) and Cy5 (Acceptor, A) absorption spectra are shown as dashed lines, and emission spectra are coloured yellow (Cy3) and orange (Сy5). Сy3 was excited at $514 \mathrm{~nm}$ (543 nm in experiments also containing GFPs; Fig. 4b and Supplementary Fig. 4aii) and Cy5 was excited at $633 \mathrm{~nm}$. Grey rectangles indicate the wavelengths over which fluorescence emission was typically collected. ii, Single xy slices extracted at equivalent positions from the fluorescence zstacks recorded during a representative FRET experiment. iii, z-axis profiles of the respective fluorescence image stacks. Coloured bars indicate the regions of the image stacks used in the analysis. 

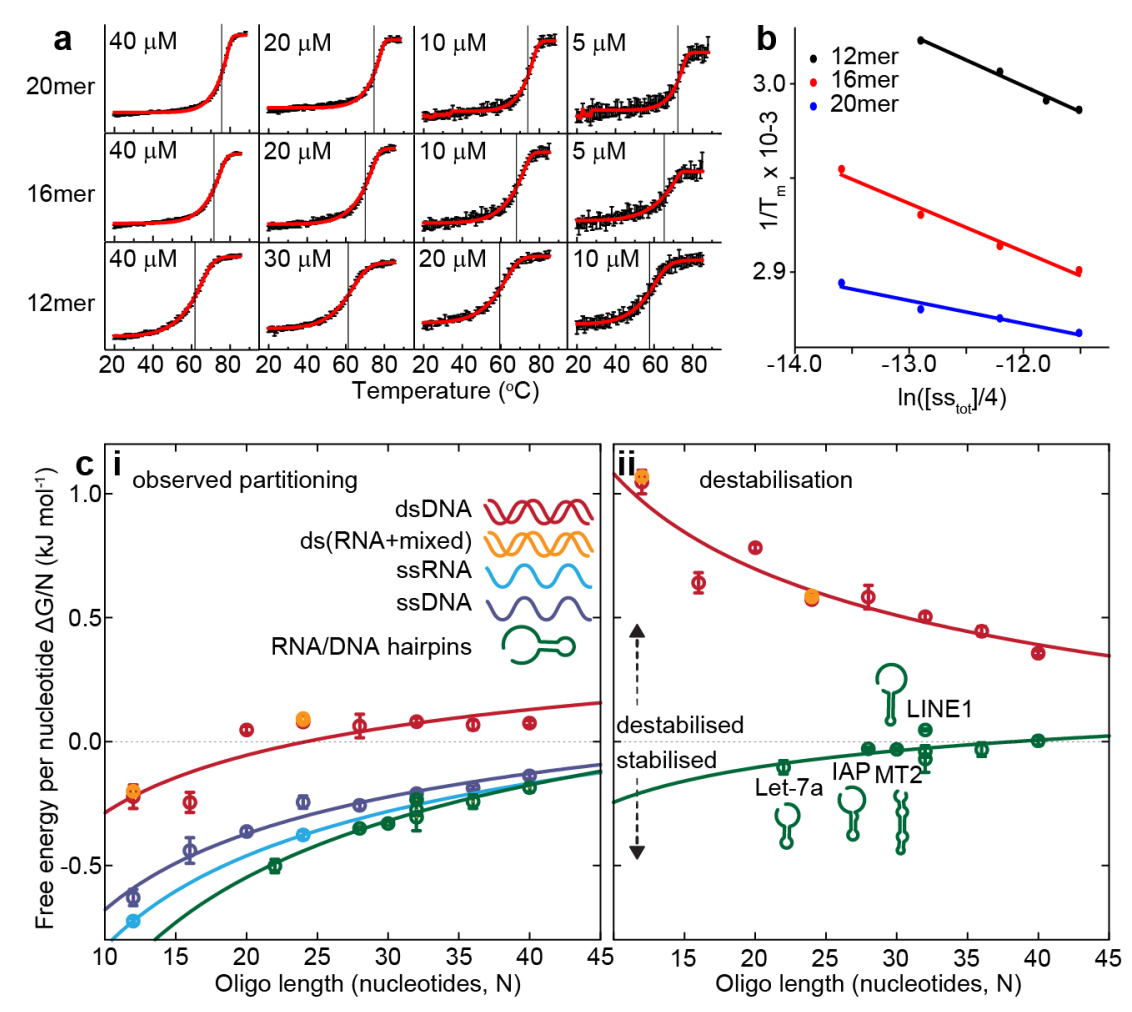

Supplementary Figure 3| a, Annealing profiles of the 12mer, 16mer and 20mer ACTG dsDNA. Vertical bars show the midpoint of the curve, at which the sample contains $50 \%$ duplex. $\mathbf{b}$, The points and total concentration can be used together to get an experimental estimate of $\Delta G_{\text {stab }}$ (see Methods). c, The free energy per nucleotide is observed to decrease with oligonucleotide length, with a scaling consistent with a model of topological frustration (solid lines, see Methods). Both double and single stranded DNA, and hairpin and unstructured RNA/DNA were found to have very different partition free energies (i). This can be explained by destabilisation of the structure inside the organelles (ii). The destabilisation free energy per nucleotide is shown. The free energy per individual base pair for each of the processes is reduced with length, consistent with topological frustration inside the liquid drops ${ }^{25}$. Errors are the same as in Fig 1c. 


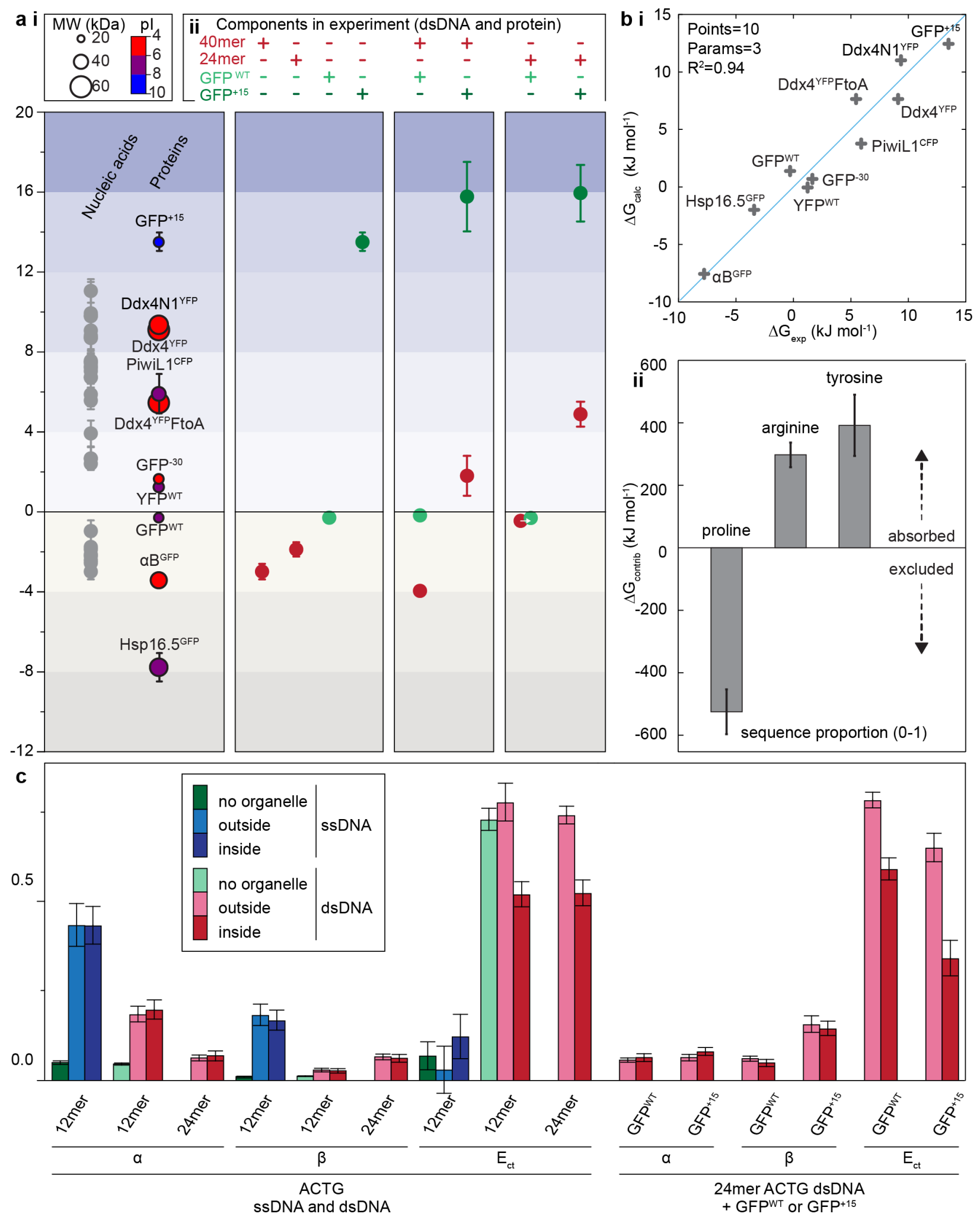

Supplementary Figure $4 \mid$ a, Ddx4 $4^{\mathrm{N} 1}$ organelles differentially partition proteins, which in turn can act as chaperones to import and unwind dsDNA. ai, Partitioning of proteins and nucleic acids. ii, GFP ${ }^{+15}$ can chaperone otherwise excluded duplexes inside $\mathrm{Ddx} 4^{\mathrm{N} 1}$ organelles. Error bars show the standard 
deviation of at least 30 measurements from 2 independent sample preparations. bi, Correlation between experimentally determined partition free energies, and those calculated through a sequence analysis. Including only three properties of the protein sequence is sufficient to calculate the partition free energy of the dataset with an $\mathrm{R}^{2}$ of 0.94 . ii, The optimised coefficients required to obtain the correlation shown (Supplementary Table 2). Knowledge of the proportion of proline, arginine and tyrosine in the protein sequence is sufficient to predict the protein partition free energy. The errors bars in the fitted coefficients were determined using a numerical bootstrapping procedure. In brief, 1000 synthetic datasets were obtained by the original data with replacement such that the total number of data points was the same. The mean and standard deviation of the fitted coefficients were taken to be the mean value and uncertainty value respectively. c, Summary of all FRET data in the study, including correction factors and corrected FRET ( $E_{c t}$ ) values (see Supplementary Table 7). Error bars show the standard deviation of at least 30 measurements from 2 independent sample preparations. 
Supplementary Tables

Supplementary Table 1: Summary of sequence identity, predicted stabilities and experimentally determined partition free energies of the oligonucleotides studied here (Figs. 1, 3). The uncertainties in

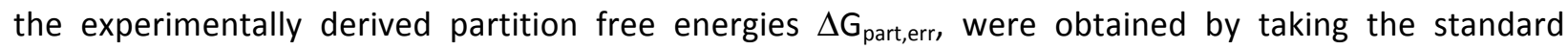
deviation of the partitioning of 30 organelles ( 5 per field of view (FOV), 3 FOVs per sample, 2 samples) per oligonucleotide (see Methods).

\begin{tabular}{|c|c|c|c|c|c|c|c|}
\hline Label & $\begin{array}{l}\text { Length } \\
\text { (bp) }\end{array}$ & $\Delta \mathrm{G}_{\text {stab,ds_- }}\left(\mathrm{kJmol}^{-1}\right)$ & $\begin{array}{l}\Delta \mathrm{G}_{\text {stab,ss- }} \\
\left(\mathrm{kJmol}^{-1}\right)\end{array}$ & $\Delta \mathrm{G}_{\text {part }}\left(\mathrm{kJmol}^{-1}\right)$ & $\Delta \mathrm{G}_{\text {part,err }}\left(\mathrm{kJmol}^{-1}\right)$ & sequence (sense strand) & $\begin{array}{c}\text { sequence (additional } \\
\text { strand) }\end{array}$ \\
\hline dsDNA_ACTG & 12 & $\begin{array}{c}-57.8 \\
(-64.04 \pm 4.89) \\
\end{array}$ & +15.4 & 2.67 & 0.57 & [CY5]ACTGACTGACTG & CAGTCAGTCAGT \\
\hline dsDNA_ACTG & 16 & $\begin{array}{c}-81.6 \\
(-75.43 \pm 7.82)\end{array}$ & +15.1 & 3.93 & 0.65 & [Cy5]ACTGACTGACTGACTG & CAGTCAGTCAGTCAGT \\
\hline dsDNA_ACTG & 20 & $\begin{array}{c}-105.5 \\
(-132.35 \pm 20.63)\end{array}$ & +15.1 & -0.95 & -0.28 & [Cy5]ACTGACTGACTGACTGACTG & CAGTCAGTCAGTCAGTCAGT \\
\hline dsDNA_ACTG & 24 & -129.3 & +15.1 & -1.88 & -0.36 & $\begin{array}{l}\text { [CY5]ACTGACTGACTGACTGACTG } \\
\text { ACTG }\end{array}$ & CAGTCAGTCAGTCAGTCAGTCAGT \\
\hline dsDNA_ACTG & 28 & -153.2 & +15.1 & -1.75 & -1.33 & $\begin{array}{l}\text { [Cy5]ACTGACTGACTGACTGACTG } \\
\text { ACTGACTG }\end{array}$ & $\begin{array}{l}\text { CAGTCAGTCAGTCAGTCAGTCAGT } \\
\text { CAGT }\end{array}$ \\
\hline dsDNA_ACTG & 32 & -177.0 & +15.1 & -2.55 & -0.49 & $\begin{array}{l}\text { [Cy5]ACTGACTGACTGACTGACTG } \\
\text { ACTGACTGACTG }\end{array}$ & $\begin{array}{l}\text { CAGTCAGTCAGTCAGTCAGTCAGT } \\
\text { CAGTCAGT }\end{array}$ \\
\hline dsDNA_ACTG & 36 & -200.9 & +15.1 & -2.42 & -0.68 & $\begin{array}{l}\text { [Cy5]ACTGACTGACTGACTGACTG } \\
\text { ACTGACTGACTGACTG }\end{array}$ & $\begin{array}{l}\text { CAGTCAGTCAGTCAGTCAGTCAGT } \\
\text { CAGTCAGTCAGT }\end{array}$ \\
\hline dsDNA_ACTG & 40 & -224.7 & +15.1 & -2.99 & -0.39 & $\begin{array}{l}\text { [Cy5]ACTGACTGACTGACTGACTG } \\
\text { ACTGACTGACTGACTGACTG }\end{array}$ & $\begin{array}{l}\text { CAGTCAGTCAGTCAGTCAGTCAGT } \\
\text { CAGTCAGTCAGTCAGT }\end{array}$ \\
\hline SSDNA_ACTG & 12 & +9.9 & +15.4 & 7.55 & 0.39 & [CY5]ACTGACTGACTG & ACTGACTGACTG \\
\hline ssDNA_ACTG & 16 & +9.9 & +15.1 & 7.04 & 0.83 & [Cy5]ACTGACTGACTGACTG & ACTGACTGACTGACTG \\
\hline ssDNA_ACTG & 20 & +9.9 & +15.1 & 7.27 & 0.33 & [Cy5]ACTGACTGACTGACTGACTG & ACTGACTGACTGACTGACTG \\
\hline ssDNA_ACTG & 24 & +9.9 & +15.1 & 5.87 & 0.59 & $\begin{array}{l}\text { [CY5]ACTGACTGACTGACTGACTG } \\
\text { ACTG }\end{array}$ & ACTGACTGACTGACTGACTGACTG \\
\hline ssDNA_ACTG & 28 & +9.9 & +15.1 & 7.20 & 0.47 & $\begin{array}{l}\text { [CY5]ACTGACTGACTGACTGACTG } \\
\text { ACTGACTG }\end{array}$ & $\begin{array}{l}\text { ACTGACTGACTGACTGACTGACTG } \\
\text { ACTG }\end{array}$ \\
\hline ssDNA_ACTG & 32 & +9.9 & +15.1 & 6.71 & 0.31 & $\begin{array}{l}\text { [Cy5]ACTGACTGACTGACTGACTG } \\
\text { ACTGACTGACTG }\end{array}$ & $\begin{array}{l}\text { ACTGACTGACTGACTGACTGACTG } \\
\text { ACTGACTG }\end{array}$ \\
\hline ssDNA_ACTG & 36 & +9.9 & +15.1 & 6.73 & 0.29 & $\begin{array}{l}\text { [CY5]ACTGACTGACTGACTGACTG } \\
\text { ACTGACTGACTGACTG }\end{array}$ & $\begin{array}{l}\text { ACTGACTGACTGACTGACTGACTG } \\
\text { ACTGACTGACTG }\end{array}$ \\
\hline ssDNA_ACTG & 40 & +9.9 & +15.1 & 5.56 & 0.44 & $\begin{array}{l}\text { [CY5]ACTGACTGACTGACTGACTG } \\
\text { ACTGACTGACTGACTGACTG }\end{array}$ & $\begin{array}{l}\text { ACTGACTGACTGACTGACTGACTG } \\
\text { ACTGACTGACTGACTG }\end{array}$ \\
\hline dsRNA_ACUG & 12 & -87.6 & +7.6 & 2.41 & 0.14 & [CY5]ACUGACUGACUG & CAGUCAGUCAGU \\
\hline dsRNA_ACUG & 24 & -203.2 & +7.6 & -2.13 & 0.14 & $\begin{array}{l}\text { [Cy5]ACUGACUGACUGACUGACU } \\
\text { GACUG }\end{array}$ & $\begin{array}{l}\text { CAGUCAGUCAGUCAGUCAGUCA } \\
\text { GU }\end{array}$ \\
\hline dsRNA/DNA_hybrid & 24 & -203.2 & +7.6 & -2.21 & 0.07 & $\begin{array}{l}\text { [CY5]ACUGACUGACUGACUGACU } \\
\text { GACUG }\end{array}$ & CAGTCAGTCAGTCAGTCAGTCAGT \\
\hline ssRNA_ACUG & 12 & +7.9 & +7.6 & 8.69 & 0.12 & [CY5]ACUGACUGACUG & ACUGACUGACUG \\
\hline ssRNA_ACUG & 24 & +7.9 & +7.6 & 9.06 & 0.38 & $\begin{array}{l}\text { [Cy5]ACUGACUGACUGACUGACU } \\
\text { GACUG }\end{array}$ & $\begin{array}{l}\text { ACUGACUGACUGACUGACUGAC } \\
\text { UG }\end{array}$ \\
\hline 6bpDNA_hairpin & 32 & -40.3 & -28.68 & 8.81 & 0.75 & $\begin{array}{l}\text { [Cy3]GGCGGCTTTTTTTTTTTTTTT } \\
\text { TTTTTGCCGCC[Cy5] }\end{array}$ & \\
\hline 6bpRNA_hairpin & 32 & -56.5 & -50.28 & 9.79 & 1.72 & $\begin{array}{l}\text { [Cy3]GGCGGCUUUUUUUUUUUU } \\
\text { UUUUUUUUGCCGCC[Cy5] }\end{array}$ & \\
\hline 8bpDNA_hairpin & 36 & -58.1 & -46.22 & 8.72 & 0.98 & $\begin{array}{l}\text { [Cy3]GGCGGCGGTTTTTTTTTTTTT } \\
\text { TTTTTTTCCGCCGCC[CY5] }\end{array}$ & \\
\hline 10bpDNA_hairpin & 40 & -95.0 & -65.52 & 7.44 & 0.70 & $\begin{array}{l}\text { [CY3]GGCGGCGGCGTTTTTTTTTT } \\
\text { TTTTTTTTTTCGCCGCCGGC[CY5] }\end{array}$ & \\
\hline Let-7a_RNA_hairpin & 22 & -16.9 & -4.44 & 11.05 & 0.59 & $\begin{array}{l}\text { [CY5]UGAGGUAGUAGGUUGUAU } \\
\text { AGUU }\end{array}$ & \\
\hline IAP_28_RNA_hairpin & 28 & -33.7 & -9.67 & 9.81 & 0.18 & $\begin{array}{l}\text { [Cy5]UACCACUUAGAACACAGGA } \\
\text { UGUCAGCGC }\end{array}$ & \\
\hline $\begin{array}{c}\text { MT2_30_RNA_hairpi } \\
n\end{array}$ & 30 & -76.0 & -23.19 & 9.94 & 0.21 & $\begin{array}{l}\text { [CY5]UGUGAAUGGAAGUCCAAG } \\
\text { GAUCUAGCAGUU }\end{array}$ & \\
\hline $\begin{array}{c}\text { LINE1_32_RNA_hairp } \\
\text { in }\end{array}$ & 32 & -57.2 & -28.89 & 7.51 & 0.15 & $\begin{array}{l}\text { [CY5]UGAAACUCCAAAGUUUCUC } \\
\text { CAAGGCAAAAGAC }\end{array}$ & \\
\hline
\end{tabular}


Supplementary Table 2: Summary of concentrations of proteins used in partitioning experiments and sequence properties. The experimental free energies are shown together with a result derived from the equation $\Delta G_{\text {calc }}=\alpha[$ Pro\% $]+\beta[$ Arg\% $]+\chi\left[\right.$ Tyr\%] where $\alpha=-0.524, \beta=0.297$ and $\chi=0.392 \mathrm{kJmol}^{-1}$ were optimised co-factors (Supplementary Fig. 4a).

\begin{tabular}{|c|c|c|c|c|c|c|c|c|c|c|c|c|}
\hline & $\begin{array}{c}\text { Conc in } \\
\text { droplet } \\
(\mu \mathrm{M})\end{array}$ & $\begin{array}{c}\Delta \mathrm{G}_{\text {part }} \\
\text { (kJ } \\
\mathrm{mol}^{-} \\
\left.{ }^{1}\right) \\
\end{array}$ & $\begin{array}{l}\Delta G_{\text {part,err }} \\
\left(\begin{array}{c}(\mathrm{kJ} \mathrm{mol} \\
\left.{ }^{1}\right)\end{array}\right.\end{array}$ & $\begin{array}{c}\Delta \mathrm{G}_{\text {part,calc }} \\
(\mathrm{kJ} \text { mol } \\
1 \text { ) }\end{array}$ & $\begin{array}{c}\mathrm{NaCl} \\
\text { conc } \\
\text { (mM) }\end{array}$ & $\begin{array}{l}\text { length } \\
\text { (aa) }\end{array}$ & $\begin{array}{l}\text { Monomer } \\
\text { MW (kDa) }\end{array}$ & $\begin{array}{l}\text { Oligomer MW } \\
\text { (kDa) }\end{array}$ & $\mathrm{PI}$ & $\begin{array}{l}\text { Pro } \\
\text { (\%) }\end{array}$ & $\begin{array}{l}\text { Arg } \\
(\%)\end{array}$ & $\begin{array}{l}\text { Tyr } \\
\text { (\%) }\end{array}$ \\
\hline $\mathrm{Ddx} 4^{\mathrm{N} 1}$ & 162.5 & & & & & 250 & 26.7 & - & 5.43 & 4.0 & 9.6 & 2.0 \\
\hline Ddx4N1YFP & 10 & 9.4 & 0.1 & 11.0 & 150 & 474 & 52.1 & - & 5.59 & 4.0 & 6.3 & 3.4 \\
\hline Ddx4YFP & 10 & 9.1 & 0.1 & 7.6 & 150 & 535 & 58.6 & - & 5.54 & 4.3 & 6.0 & 3.2 \\
\hline Ddx4YFP_FtoA & 10 & 5.5 & 0.1 & 7.6 & 150 & 535 & 57.8 & - & 5.54 & 4.3 & 6.0 & 3.2 \\
\hline PiwiL1 CFP & 10 & 5.9 & 1.0 & 3.8 & 150 & 347 & 38.1 & - & 7.91 & 4.6 & 6.1 & 2.6 \\
\hline YFP & 10 & 1.2 & 0.1 & -4.6 & 150 & 261 & 29.3 & - & 6.07 & 5.0 & 3.1 & 4.2 \\
\hline GFP $^{W T}$ & 5 & -0.29 & 0.1 & 1.4 & 150 & 239 & 26.9 & - & 6.33 & 4.2 & 3.3 & 3.3 \\
\hline $\mathrm{GFP}^{-30}$ & 5 & 1.6 & 0.2 & 0.7 & 150 & 245 & 27.7 & - & 4.64 & 4.1 & 2.4 & 3.7 \\
\hline $\mathrm{GFP}^{+15}$ & 5 & 13.5 & 0.5 & 12.4 & 150 & 245 & 28.1 & - & 9.75 & 4.1 & 6.5 & 3.7 \\
\hline aB-GFP & 11.8 & -7.8 & 0.7 & -7.6 & 175 & 433 & 49.2 & 1,378 (28mer) & 6.27 & 6.2 & 4.8 & 2.8 \\
\hline sHSP16.5-GFP & 17.3 & -3.4 & 0.3 & -2.0 & 175 & 405 & 45.6 & 1,092 (24mer) & 5.73 & 4.4 & 3.2 & 3.0 \\
\hline
\end{tabular}




\section{Supplementary Table 3: Summary of protein sequences used in this study.}

\begin{tabular}{|c|c|}
\hline $\mathrm{Ddx} 4^{\mathrm{N} 1}$ & $\begin{array}{l}\text { AMGSMGDEDWEAEINPHMSSYVPIFEKDRYSGENGDNFNRTPASSSEMDDGPSRRDHFMKSGFASGRNFGNRDAGECNKRDNTSTMGGFGVGKSFGNRGFSNSRFEDGDSSGFWRESSNDCEL } \\
\text { RNRGFSKRGGYRDGNNSEASGPYRRGGRGSFRGCRGGFGLGSPNNDLDPDECMQRTGGLFGSRRPVLSGTGNGDTSQSRSGSGSERGGYKGLNEEVITGSGKNSWKSEAEGGESSDTQGPKVT }\end{array}$ \\
\hline GFP $^{\text {WT }}$ & $\begin{array}{l}\text { HHHHHHMSKGEELFTGVVPILVELDGDVNGHKFSVRGEGEGDATNGKLTLKFICTTGKLPVPWPTLVTTLGYGVQCFSRYPDHMKRHDFFKSAMPEGYVQERTISFKDDGTYKTRAEVKFEGDTLVNRIEL } \\
\text { IIDFKEDGNILGHKLEYNFNSHNVYITADKQKNGIKANFKIRHNVEDGSVQLADHYQQNTPIGDGPVLLPDNHYLSTQSVLSKDPNEKRDHMVLLEFVTAAGITHG }\end{array}$ \\
\hline $\mathrm{GFP}^{+15}$ & $\begin{array}{l}\text { MHHHHHHMSKGERLFTGVVPILVELDGDVNGHKFSVRGEGEGDATRGKLTLKFICTTGKLPVPWPTLVTTLTYGVQCFSRYPKHMKRHDFFKSAMPEGYVQERTISFKKDGTYKTRAEVKFEGRTLVNRIELK } \\
\text { GRDFKEKGNILGHKLEYNFNSHNVYITADKRKNGIKANFKIRHNVKDGSVQLADHYQQNTPIGRGPVLLPRNHYLSTRSALSKDPKEKRDHMVLLEFVTAAGITHGMDELYK }\end{array}$ \\
\hline GFP $^{-30}$ & $\begin{array}{l}\text { MHHHHHHMSKGEELFDGVVPILVELDGDVNGHEFSVRGEGEGDATEGELTLKFICTTGELPVPWPTLVTTLTYGVQCFSDYPDHMDQHDFFKSAMPEGYVQERTISFKDDGTYKTRAEVKFEGDTLVNRIEL } \\
\text { KGIDFKEDGNILGHKLEYNFNSHDVYITADKQENGIKAEFEIRHNVEDGSVQLADHYQQNTPIGDGPVLLPDDHYLSTESALSKDPNEDRDHMVLLEFVTAAGIDHGMDELYK }\end{array}$ \\
\hline $\mathrm{Ddx} 4^{\mathrm{N} 1} \mathrm{YFP}$ & $\begin{array}{l}\text { GAMGSMGDEDWEAEINPHMSSYVPIFEKDRYSGENGDNFNRTPASSSEMDDGPSRRDHFMKSGFASGRNFGNRDAGECNKRDNTSTMGGFGVGKSFGNRGFSNSRFEDGDSSGFWRESSNDCEDNP } \\
\text { TRNRGFSKRGGYRDGNNSEASGPYRRGGRGSFRGCRGGFGLGPNNDLDPDECMQRTGGLFSRRPVLSGTGNGDTSQSRSGSGSERGGYKGLNEEVITGSGKNSWKSEAEGGESVDMVSKGEELFTGV } \\
\text { VPILVELDGDVNGHKFSVSGEGEGDATYGKLTLKFICTTGKLPVPWPTLVTTFGYGLMCFARYPDHMKQHDFFKSAMPEGYVQERTIFFKDDGNYKTRAEVKFEGDTLVNRIELKGIDFKEDGNILGHKLEYNY } \\
\text { NSHNVYIMADKQKNGIKVNFKIRHNIEDGSVQLADHYQNTPIGDGPVLLPDNHYLSYQSKLSKDPNEKRDHMVLLFVTAAGIT }\end{array}$ \\
\hline $\mathrm{Ddx} 4^{\mathrm{YFP}}$ & $\begin{array}{l}\text { GAMGSNMGDEDWEAEINPHMSSYVPIFEKDRYSGENGDNFNRTPASSSEMDDGPSRRDHFMKSGFASGRNFGNRDAGECNKRDNTSTMGGFGVGKSFGNRGFSNSRFEDGDSSGFWRESSNDCEDN } \\
\text { PTRNRGFSKRGGYRDGNNSEASGPYRRGGRGSFRGCRGGFGLGSPNNDLDPDECMQRTGGLFGSRRPVLSGTGNGDTSQSRSGSGSERGGYKGLNEEVITGSGKNSWKSEAEGGESSDTQGPKVTLQMV } \\
\text { SKGEELFTGVVPILVELDGDVNGHKFSVSGEGEGDATYGKLTLKFICTTGKLPVPWPTLVTTFGYGLMCFARYPDHMKOHDFFKSAMPEGYVQERTIFFKDDGNYKTRAEVKFEGDTLVNRIELKGIDFKEDG } \\
\text { NILGHKLEYNYNSHNVYIMADKQKNGIKVNFKIRHNIEDGSVQLADHYQNTPIGDGPVLLPDNHYLSYQSKLSKDPNEKRDHMVLLEFVTAAGITLEFSTYIPGFSGSTRGNVFASVDTRKGKSTLNTAGFSSS } \\
\text { QAPNPVDDESWD }\end{array}$ \\
\hline $\mathrm{Ddx}_{\mathrm{A}}^{\mathrm{YFP}}$ Fto & $\begin{array}{l}\text { GAMGSNMGDEDWEAEINPHMSSYVPIFEKDRYSGENGDNFNRTPASSSEMDDGPSRRDHFMKSGAASGRNAGNRDAGECNKRDNTSTMGGAGVGKSAGNRGASNSRFEDGDSSGFWRESSNDCED } \\
\text { NPTRNRGASKRGGYRDGNNSEASGPYRRGGRGSARGCRGGAGLGSPNNDLDPDECMQRTGGLAGSRRPVLSGTGNGDTSQSRSGSGSERGGYKGLNEEVITGSGKNSWKSEAEGGESSDTQGPKVTLQ } \\
\text { MVSKGEELFTGVVPILVELDGDVNGHKFVSGEGEGDATYGKLTLKFICTTGKLPVPPTLVTTFGYGLMCFARYPDHMKQHDFFKSAMPEGYVQERTIFFKDDGNYKTRAEVKFEGDTLVNRIELKGIDFKE } \\
\text { DGNILGHKLEYNYNSHNVIMADKQKNGIKVNFKIRHNIEDGSVQLADHYQQNTPIGDGPVLLPDNHYLSYQSKLSKDPNEKRDHMVLLEFVTAAGITLEASTYIPGASGSTRGNVFASVDTRKGKSTLNTAG } \\
\text { FSSSQAPNPVDDESWD }\end{array}$ \\
\hline YFP & $\begin{array}{l}\text { GAMGSMVSKGEELFTGVVPILVELDGDVNGHKFSVSGEGEGDATYGKLTLKFICTTGKLPVPWPTLVTTFGYGLMCFARYPDHMKQHDFFKSAMPEGYVQERTIFFKDDGNYKTRAEVKFEGDTLVNRIELK } \\
\text { GIDFKEDGNILGHKLEYNYNSHNVYIMADKQKNGIKVNFKIRHNIEDGSVQLADHYQQNTPIGDGPVLLPDNHYLSYQSKLSKDPNEKRDHMVLLEFVTAAGITLERPLSNLEPAVSRHAVPSFKLSNN }\end{array}$ \\
\hline $\begin{array}{l}\text { SHSP16.5 } \\
\text { GFP }\end{array}$ & $\begin{array}{l}\text { MFGRDPFDSLFERMFKEFFATPMTGTTMIQSSTGIQISGKGFMPISIIEGDQHIKVIAWLPGVNKEDIILNAVGDTLEIRAKRSPLMITESERIIYSEIPEEEEIYRTIKLPATVKEENASAKFENGVLSVILPKAESSIK } \\
\text { KGINIEASGENLYFQSLSKGEELFTGVVPILVELDGDVNGHKFSVRGEGEGDATNGKLTLKFICTTGKLPVPWPTLVTTLTYGVQCFSRYPDHMKQHDFFKSAMPEGYVQERTISFKDDGTYKTRAEVKFEGDT } \\
\text { LVNRIELKGIDFKEDGNILGHKLEYNFNSHNVYITADKQKNGIKANFKIRHNVEDGSVQLADHYQNTPIGDGPVLLPDNHYLSTQSVLSKDPNEKRDHMVLLEFVTAAGITHGMDELYKKGLEHHHHHH }\end{array}$ \\
\hline$\alpha B^{G F P}$ & $\begin{array}{l}\text { MDIAIHHPWIRRPFFPFHSPSRLFDQFFGEHLLESDLFPTSTSLSPFYLRPPSFLRAPSWFDTGLSEMRLEKDRFSVNLDVKHFSPEELKVKVLGDVIEVHGKHEERQDEHGFISREFHRKYRIPADVDPLTITSSLS } \\
\text { SDGVLTVNGPRKQVSGPERTIPITREEKPAVTAAPKKASGENLYFQSLSKGEELFTGVVPILVELDGDVNGHKFSVRGEGEGDATNGKLTLKFICTTGKLPVPWPTLVTTLTYGVQCFSRYPDHMKQHDFFKSA } \\
\text { MPEGYVQERTISFKDDGTYKTRAEVKFEGDTLVNRIELKGIDFKEDGNILGHKLEYNFNSHNVYITADKQKNGIKANFKIRHNVEDGSVQLADHYQQNTPIGDGPVLLPDNHYLSTQSVLSKDPNEKRDHMVL } \\
\text { LEFVTAAGITHGMDELYKKGLEHHHHHH }\end{array}$ \\
\hline PiwiL1 $^{\text {CFP }}$ & $\begin{array}{l}\text { GAMGSMTGRARARARGRARGQETAQLVGSTASQQPGYIQPRPQPPPAEGELFGRGRQRGTAGGTAKSQGLQISAGFQELSLAERGGRRRDFHDLGVNTRQNLDHVKESKTGSSGVDMVSKGEELFTGV } \\
\text { VPILVELDGDVNGHKFSVSGEGEGDATYGKLTLKFICTTGKLPVPWPTLVTTLTWGVQCFARYPDHMKQHDFFKSAMPEGYVQERTIFFKDDGNYKTRAEVKFEGDTLVNRIELKGIDFKEDGNILGHKLEYN } \\
\text { AISDNVYITADKQKNGIKANFKIRHNIEDGSVQLADHYQQNTPIGDGPVLLPDNHYLSTQSKLSKDPNEKRDHMVLLEFVTAAGIT }\end{array}$ \\
\hline DDX3X & $\begin{array}{l}\text { GAMGSMSHVAVENALGLDQQFAGLDLNSSDNQSGGSTASKGRYIPPHLRNREATKGFYDKDSSGWSSSKDKDAYSSFGSRSDSRGKSSFFSDRGSGSRGRFDDRGRSDYDGIGSRGDRSGFGKFERGGNS } \\
\text { RWCDKSDEDDWS }\end{array}$ \\
\hline EWSR1 & $\begin{array}{l}\text { GAMGSMNSMRGGLPPREGRGMPPPLRGGPGGPGGPGGPMGRMGGRGGDRGGFPPRGPRGSRGNPSGGGNVQHRAGDWQCPNPGCGNQNFAWRTECNQCKAPKPEGFLPPPFPPPGGDRGRG } \\
\text { GPGGMRGGRGGLMDRGGPGGMFRGGRGGDRGGFRGGRGMDRGGFGGGRRGGPGGPPGPLMEQMGGRRGGRGGPGKMDKGEHRQERRDRPY }\end{array}$ \\
\hline EIF4H & FRDDFLGGRGGSRPGDRRTGPPMGSRFRDGPPLRGSNMDFREPTEEERAQRPRLQLKPRTVATPLNQVANPNSAIFGGARPREEVVQKEQE \\
\hline
\end{tabular}


Supplementary Table 4: Summary of excitation and emission schemes of fluorophores used in this study.

\begin{tabular}{|c|c|c|}
\hline Fluorophore & Excitation $(\mathrm{nm})$ & Typical emission bandwidth $(\mathrm{nm})$ \\
\hline CFP & 458 & $465-505$ \\
\hline GFP & 488 & $500-600$ \\
\hline YFP & 514 & $525-600$ \\
\hline Cy3 & 514 (543 when GFP present) & $555-620$ \\
\hline Cy5 & 633 & $650-750$ \\
\hline
\end{tabular}


Supplementary Table 5: Summary of the fitting parameters describing topological frustration in free energies the system (see Methods).

\begin{tabular}{|l|c|c|}
\hline & $\mathbf{a}$ & $\mathbf{b}$ \\
\hline$\Delta G_{\text {destab }}$ & $-2.13+/-0.26$ & $7.85+/-0.75$ \\
\hline$\Delta G_{\text {part }}$ ss & $0.81+/-0.09$ & $-3.20+/-0.25$ \\
\hline$\Delta G_{\text {part }}$ ds & $2.43+/-0.60$ & $0.84+/-0.21$ \\
\hline
\end{tabular}


Supplementary Table 6: Summary of oligos used for FRET experiments (Fig. 2aiii, and Fig. 4bii). No significant differences in partitioning were observed for these constructs when compared to those investigated in Fig. 1c.

\begin{tabular}{|c|c|c|c|}
\hline label & $\begin{array}{l}\text { Length } \\
\text { (bp) }\end{array}$ & sequence (sense strand) & sequence (additional strand) \\
\hline dsDNA_ACTG_FRET & 12 & [Cy5]ACTGACTGACTG & CAGTCAGTCAGT[Cy3] \\
\hline dsDNA_ACTG_DONOR & 12 & ACTGACTGACTG & CAGTCAGTCAGT[Cy3] \\
\hline dsDNA_ACTG_ACCEPTOR & 12 & [Cy5]ACTGACTGACTG & CAGTCAGTCAGT \\
\hline SSDNA_ACTG_FRET & 12 & [Cy5]ACTGACTGACTG & ACTGACTGACTG[Cy3] \\
\hline SSDNA_ACTG_DONOR & 12 & ACTGACTGACTG & ACTGACTGACTG[Cy3] \\
\hline SSDNA_ACTG_ACCEPTOR & 12 & [Cy5]ACTGACTGACTG & ACTGACTGACTG \\
\hline dsDNA_ACTG_FRET & 24 & [Cy5]ACTGACTGACTGACTGACTGACTG & CAGTCAGTCAGTCAGTCAGTCAGT[Cy3] \\
\hline dsDNA_ACTG_DONOR & 24 & ACTGACTGACTGACTGACTGACTG & CAGTCAGTCAGTCAGTCAGTCAGT[Cy3] \\
\hline dsDNA_ACTG_ACCEPTOR & 24 & [Cy5]ACTGACTGACTGACTGACTGACTG & CAGTCAGTCAGTCAGTCAGTCAGT \\
\hline
\end{tabular}


Supplementary Table 7: Summary of correction factors and FRET measurements for double and single stranded DNA, inside, outside and in the absence of organelles from confocal microscopy measurements.

\begin{tabular}{|c|c|c|c|c|c|c|}
\hline & outside & err & inside & err & $\begin{array}{c}\text { Organelle } \\
\text { free }\end{array}$ & err \\
\hline$\alpha$ (ss 12mer) & 0.434 & 0.06 & 0.433 & 0.053 & 0.05 & 0.005 \\
\hline$\alpha$ (ds 12mer) & 0.184 & 0.022 & 0.197 & 0.027 & 0.046 & 0.003 \\
\hline$\alpha$ (ds 24mer) & 0.063 & 0.008 & 0.069 & 0.014 & & \\
\hline$\beta$ (ss 12mer) & 0.182 & 0.030 & 0.167 & 0.028 & 0.011 & 0.001 \\
\hline$\beta$ (ds 12mer) & 0.029 & 0.005 & 0.027 & 0.006 & 0.012 & 0.001 \\
\hline$\beta$ (ds 24mer) & 0.066 & 0.008 & 0.062 & 0.011 & & \\
\hline$E_{C T}$ (ss 12mer) & 0.029 & 0.065 & 0.122 & 0.061 & 0.068 & 0.038 \\
\hline$E_{C T}$ (ds 12mer) & 0.778 & 0.053 & 0.52 & 0.035 & 0.73 & 0.031 \\
\hline$E_{C T}$ (ds 24mer) & 0.742 & 0.025 & 0.524 & 0.036 & & \\
\hline & outside & err & inside & err & & \\
\hline$\alpha$ (ds 24mer + GFP ${ }^{\mathrm{WT}}$ ) & 0.057 & 0.006 & 0.064 & 0.011 & & \\
\hline$\alpha$ (ds 24mer $+\mathrm{GFP}^{+15}$ ) & 0.064 & 0.009 & 0.08 & 0.01 & & \\
\hline$\beta$ (ds 24mer + GFP ${ }^{\mathrm{WT}}$ ) & 0.061 & 0.007 & 0.049 & 0.01 & & \\
\hline$\beta$ (ds 24mer $+\mathrm{GFP}^{+15}$ ) & 0.156 & 0.023 & 0.144 & 0.02 & & \\
\hline$E_{C T}$ (ds 24mer $+\mathrm{GFP}^{\mathrm{WT}}$ ) & 0.784 & 0.022 & 0.591 & 0.031 & & \\
\hline$E_{C T}$ (ds 24mer $+\mathrm{GFP}^{+15}$ ) & 0.651 & 0.04 & 0.341 & 0.05 & & \\
\hline
\end{tabular}


Supplementary Table 8: A summary of $R_{A}$ values obtained as a function of $\mathrm{GdmHCl}$ concentration.

\begin{tabular}{|c|c|c|}
\hline & {$[\mathrm{GdmHCl}](\mathrm{M})$} & $R_{A}$ \\
\hline ssDNA 12mer & 0 & 0.029401 \\
\hline dsDNA 12mer & 6 & 0.180777 \\
\hline dsDNA 12mer & 5 & 0.275138 \\
\hline dsDNA 12mer & 4 & 0.301041 \\
\hline dsDNA 12mer & 3 & 0.403414 \\
\hline dsDNA 12mer & 0.3 & 0.422269 \\
\hline dsDNA 12mer & 0 & 0.447617 \\
\hline
\end{tabular}




\section{Supplementary References}

32. Pedelacq, J. D., Cabantous, S., Tran, T., Terwilliger, T. C. \& Waldo, G. S. Engineering and characterization of a superfolder green fluorescent protein. Nat. Biotechnol. 24, 79-88, (2006).

33. Cao, J. F., Wu, T., Hu, C., Liu, T., Sun, W. et al. The nature of the different environmental sensitivity of symmetrical and unsymmetrical cyanine dyes: an experimental and theoretical study. Phys. Chem. Chem. Phys. 14, 13702-13708, (2012).

34. Muddana, H. S., Morgan, T. T., Adair, J. H. \& Butler, P. J. Photophysics of Cy3-Encapsulated Calcium Phosphate Nanoparticles. Nano Lett. 9, 1559-1566, (2009).

35. Markham, N. R. \& Zuker, M. UNAFold: software for nucleic acid folding and hybridization. Methods Mol. Biol. 453, 3-31, (2008).

36. Schindelin, J., Arganda-Carreras, I., Frise, E., Kaynig, V., Longair, M. et al. Fiji: an open-source platform for biological-image analysis. Nature methods 9, 676-682, (2012).

37. Clegg, R. M. Fluorescence Resonance Energy-Transfer and Nucleic-Acids. Methods Enzymol. 211, 353-388, (1992).

38. Gatzogiannis, E., Chen, Z. X., Wei, L., Wombacher, R., Kao, Y. T. et al. Mapping protein-specific micro-environments in live cells by fluorescence lifetime imaging of a hybrid genetic-chemical molecular rotor tag. Chem. Commun. 48, 8694-8696, (2012). 